\title{
Micro-mechanical and tribological properties of aluminum-magnesium nanocomposites processed by high-pressure torsion
}

\author{
Jae-Kyung Han ${ }^{1}$, Han-Joo Lee ${ }^{1}$, Jae-il Jang ${ }^{1} *$, Megumi Kawasaki ${ }^{1,2} *$, \\ Terence G. Langdon ${ }^{2,3}$ \\ ${ }^{1}$ Division of Materials Science \& Engineering, Hanyang University, Seoul 133-791, \\ South Korea \\ ${ }^{2}$ Departments of Aerospace \& Mechanical Engineering and Materials Science, \\ University of Southern California, Los Angeles, CA 90089-1453, U.S.A. \\ ${ }^{3}$ Materials Research Group, Faculty of Engineering and the Environment, \\ University of Southampton, Southampton SO17 1BJ, U.K.
}

\begin{abstract}
High-pressure torsion (HPT) is one of the major severe plastic deformation (SPD) procedures where bulk metals, in the shape of a disk, achieve exceptional grain refinement at ambient temperatures. HPT has been applied for the consolidation of metallic powders and the bonding of machining chips whereas there are very limited reports examining the application of HPT for the production of new metal systems and the formation of nanocomposites. Accordingly, this investigation was initiated to evaluate the potential for the formation of a metal matrix nanocomposite (MMNC) by processing two commercial metal disks of an Al1050 alloy and a ZK60 magnesium alloy through HPT under 6.0 GPa for 20 turns at room temperature. Evolutions in microstructure, mechanical properties including hardness and plasticity and the tribological properties were examined in the MMNC region of the processed Al-Mg system. The significance of post-deformation annealing (PDA) at $573 \mathrm{~K}$ for 1 hour was investigated by the change in microstructure and the enhancement in mechanical properties and wear resistance of the HPT-processed MMNC. This study demonstrates the promising feasibility of using HPT to fabricate a wide range of hybrid MMNCs from simple metals and for applying PDA for further improvement of the essential mechanical and tribological properties in the synthesized alloy systems.
\end{abstract}

Keywords: high-pressure torsion; metal matrix nanocomposite; nanoindentation; postdeformation annealing; tribology 


\section{Introduction}

The synthesis of new materials is now driven by technological issues combined with the restrictions imposed by ecological considerations in a variety of industrial applications [1]. Light-weight metals of aluminum and magnesium are widely used for structural applications in the automotive, aerospace and electronic industries and they will become the principal future structural materials if hardness and strength are improved. In practice, a recent report shows an increase in the strength limit of an aerospace-grade Al-7075 alloy by processing through high-pressure torsion (HPT) while maintaining reasonable formability [2].

Bulk nanostructured materials (BNM) having true nanometer grains can be fabricated by severe plastic deformation (SPD) which is a promising technique for achieving grain refinement in bulk metals [3]. Among the various available SPD techniques, HPT provides the potential for achieving true nanostructures [4]. The processed metals generally demonstrate an enhancement of the physical and mechanical characteristics through significant grain refinement and the intensive introduction of point and line defects [5]. The introduction of intense plastic straining by HPT has been applied also for the bonding of machining chips [6] and the consolidation of metallic powders [7-9].

Nevertheless, there is a saturation in the improved mechanical properties by grain refinement and further superior properties are not easy to obtain by processing directly on the alloy unless a subsequent SPD technique is applied to the processed material [10]. Thus, to date there are only limited numbers of demonstrations of any alternative methods of fabricating high performance material by bonding dissimilar bulk metals to form new metal systems through HPT. A first report demonstrated a solid-state reaction in an Al-Cu system through the bonding of semi-circular half-disks of $\mathrm{Al}$ and $\mathrm{Cu}$ using HPT at ambient temperature for up to 100 turns [11]. Following this, the potential for forming a spiral texture was reported by processing of an Al-Cu hybrid material though HPT where four quarter-disks, 
including two of pure $\mathrm{Cu}$ and two of an Al-6061 alloy, were positioned to make a complete disk and then processed by HPT at room temperature (RT) for 1 turn [12]. However, this study described only the computational calculation of the distribution of equivalent stress in the processed disk using a finite element method and there was no detailed microstructural analysis of the processed disk. Recently, the bonding of separate $\mathrm{Al}$ and $\mathrm{Mg}$ disks was processed through HPT by stacking a set of two disks for up to 20 turns [13] and stacking three disks for 5-10 turns [14-16] for producing bi-layered and multi-layered structures, respectively, in an $\mathrm{Al}-\mathrm{Mg}$ system through $\mathrm{HPT}$ at RT. In particular, the earlier studies focused on determining the strengthening mechanisms [14], the fast diffusivity of $\mathrm{Mg}$ in $\mathrm{Al}$ matrix [15] and the plastic instability [16] of the Al-Mg system from the bonding of three disks. It is important to note that there has been no report on the tribological properties of this newly synthesized metal system fabricated from solid metals through the application of HPT.

Accordingly, in the present study an Al-Mg hybrid system was processed from two separate $\mathrm{Al}$ and $\mathrm{Mg}$ disks by applying conventional HPT processing for 20 turns at RT. The subsequent experiments describe a detailed examination of the deformed structure, the hardness evolution and a micro-mechanical response especially showing the plasticity and tribological properties of the nanocomposite produced by HPT. The significance of postdeformation annealing (PDA) on the microstructure was investigated together with the mechanical properties in the nanocomposite region of the Al-Mg system after HPT. The study of PDA was specifically aimed to demonstrate the improvement in plasticity and the increase in the strain rate sensitivity in the synthesized Al-Mg hybrid system after HPT for 20 turns where an Al-Mg system after 10 turns demonstrated low ductility and a decreased strain rate sensitivity [16]. The results confirm the feasibility of using HPT processing in the 
preparation of new alloy systems and of incorporating PDA for an enhancement in the essential mechanical properties in the processed alloy systems.

\section{Experimental material and procedures}

Two separate bulk metals were prepared for the present study: a commercial purity $(99.5 \%)$ Al-1050 alloy and a commercial ZK60 magnesium alloy including $6.0 \mathrm{wt} \% \mathrm{Zn}$ and $0.72 \mathrm{wt} \%$

Zr. Both the Al-1050 and ZK60 alloys were received as rods after extrusion having diameters of $\sim 10 \mathrm{~mm}$ and lengths of $\sim 65 \mathrm{~mm}$. A set of disk samples was prepared from the as-extruded rod by cutting into disks with thicknesses of $\sim 2.0 \mathrm{~mm}$ and grinding both disk surfaces to a final thickness of $\sim 0.83 \mathrm{~mm}$.

Processing by HPT was conducted on the disks using a quasi-constrained HPT facility [17,18] at RT following the conventional procedure with monotonic torsional straining [19]. As described earlier [14], this study involved a unique procedure of sample set-up whereby three separate disks, in the order of $\mathrm{Al}, \mathrm{Mg}$ and $\mathrm{Al}$, were piled in the depression on the lower anvil of the HPT facility without any glue or the application of any metal blushing treatment to the disk surfaces. The HPT processing was performed to produce four disks of the Al-Mg system using a compressive pressure of $6.0 \mathrm{GPa}$ for a total revolution of 20 turns at a constant rotation speed of $1 \mathrm{rpm}$. In order to evaluate the effect of PDA, two processed disks after 20 HPT turns were annealed at $573 \mathrm{~K}$ for 1 hour.

An HPT-processed disk and a disk after HPT and PDA were cut vertically along the diameter to provide two semi-circular disks and each cross-sectional surface was mechanically polished to have a mirror-like condition. For microstructural analysis of the overall cross-sections, the polished surfaces at the vertical cross-sections were etched with Keller's etchant of $190 \mathrm{ml}$ distilled water, $5 \mathrm{ml}$ nitric acid, $3 \mathrm{ml}$ hydrochloric acid and $2 \mathrm{ml}$ hydrofluoric acid and examined using optical microscopy (OM) with a CK40M (Olympus, Japan). 
Vickers microhardness measurements were conducted to construct color-coded hardness contour maps on the polished cross-sectional surfaces of the other set of the semicircle disks. The Vickers microhardness values, Hv, on the overall cross-sections of the disks were measured at intervals of $0.15 \mathrm{~mm}$ using HMV-2 equipment (Shimadzu, Japan) with a load of $50 \mathrm{gf}$ and a dwell time of $10 \mathrm{sec}$.

The changes in the crystal structure and chemical compositions were examined with X-ray diffraction (XRD) analysis by using a high-resolution XRD system, Ultima III (Rigaku, Japan), at the horizontal disk surfaces of the highly strained regions in another set of the processed disk and the disk after HPT and PDA. Thus, the peripheral regions of these disks were examined after removing a central region with a radius of $1.5 \mathrm{~mm}$ from these disks. The diffraction patterns were obtained by using $\mathrm{CuK} \alpha$ radiation with a speed of $1 \% \mathrm{~min}$ and a step size of $0.01^{\circ}$. The analytical tool of Materials Analysis Using Diffraction (MAUD), which is an XRD data analysis software, was used for identifying and quantifying the amounts of compounds from these XRD profiles at the disk edges.

The detailed microstructural evolution was examined using transmission electron microscopy (TEM), a spherical aberration Cs-corrected JEOM-2100F (JEOL), after preparing the specimens by applying an in-situ lift-out technique using a focused ion beam (FIB), NOVA 600 Nanolab (FEI). The measurements were taken at a distance of $1 \mathrm{~mm}$ from the edges of both the HPT-processed and HPT plus PDA Al-Mg disks. High resolution compositional analysis was conducted from several specific areas using EDS in a scanning TEM (STEM) mode in the JEOM-2100F (JEOL, Japan) facility.

The micro-mechanical properties were measured using a nanoindentation facility, nanoindenter-XP (formerly MTS; now Agilent, Oak Ridge, TN), by applying a procedure of constant indentation strain rates (CSR) testing using a three sided pyramidal Berkovich indenter at the peripheral regions of the processed disk and of the disk after HPT followed by 
annealing. Practically, the samples were tested to a maximum load of $50 \mathrm{mN}$ at four different constant indentation strain rates, $\dot{\varepsilon}_{i}$, of $0.0025,0.05,0.1$ and $0.2 \mathrm{~s}^{-1}$. For each testing condition, the average properties were calculated from 20 separate measurements taken similar measurement regions.

The tribological properties were measured using a tribology tester, STM-Smart (Hanmi, Korea), with a sliding testing mode at RT for the HPT-processed Al-Mg disks for 20 HPT turns and with additional PDA treatment. For the sliding measurements, a carbon steel (SUJ-2) ball was used as the counter material where the composition of the ball included 0.95-1.10 C, 0.15-0.35 Si, 0.5 Mn, 0.025 P, 0.025 S, 1.30-1.60 Cr and 0.08 Mo (wt.\%) and showed a Rockwell hardness (HRC) value of 60-64. The small-scale sliding tests were conducted at the peripheral regions of the disks after HPT and HPT followed by PDA under a constant load of $3 \mathrm{~N}$. Thus, the counter material glided over the Al-Mg disk edges of $\mathrm{r}>4.0$ $\mathrm{mm}$ with a stroke of $2.0 \mathrm{~mm}$ at a speed of $0.004 \mathrm{~m} / \mathrm{s}(1 \mathrm{~Hz})$ and totals of 8 measurements were recorded for each sample to provide average quantitative values for the tribological properties. A schematic illustration of the measurement locations is shown in Fig. 1.

The friction coefficient was measured for each disk with a total sliding distance of 20 m. After testing, each disk sample was cleaned in an ultrasonic bath before measuring the weight-loss which is required for calculating the wear rate. The morphologies of the worn surfaces in the samples were analyzed after $1 \mathrm{~cm}$ of sliding test under the same load by using a Nanosystemz Co. NV-1000 optical interferometer and an SEM, JEOL JCM 5700.

\section{Experimental results}

\subsection{Overview of the gradient-type microstructure in the through-thickness direction}

Figure 2(a) shows optical microstructural $(\mathrm{OM})$ photos taken at the vertical crosssections and Fig. 2(b) displays the color-coded hardness contour maps of the Al-Mg disks after HPT at RT for 20 turns (upper) and after HPT followed by PDA at $573 \mathrm{~K}$ for 1 hour 
(lower), respectively. For the OM images, the bright regions denote the Al-rich phase and the dark regions correspond to the Mg-rich phase.

The disk after 20 turns by HPT gives a gradient-type microstructure where the central region towards a radius of $r \approx 2.5 \mathrm{~mm}$ shows a multi-layered formation of Al-rich and $\mathrm{Mg}$ rich phases while the outer region at $r>2.5 \mathrm{~mm}$ reveals a complete mixing of these two phases. Using conventional analysis [20-22], the outer region showing a mixture of $\mathrm{Al}$ and Mg phases has an estimated equivalent von Mises strain of 230-460 due to torsional straining and the consequent gradient structure is consistent with results reported earlier for disks processed up to 10 HPT turns [14-16].

After HPT for 20 turns and PDA in Fig. 2(a), the Al-Mg disk had a consistent gradient-type microstructure whereas the central region had a multi-layered structure expanding out to $r \approx 3.5 \mathrm{~mm}$ and, by comparison with HPT without PDA, the outer region involving the mixed phases was reduced. It should be emphasized that the observed gradienttype microstructure is essentially different from the general gradient structure in engineering materials containing a gradation in grain sizes leading to a gradual change in mechanical properties [23-25].

The hardness distribution shown in the upper map in Fig. 2(b) confirms there is a drastic gradation in the microstructure in the Al-Mg disk after HPT for 20 turns. Specifically, a Vickers microhardness of $\mathrm{Hv} \approx 60$ and slightly higher was observed at the central region of the disk at $r<2.5 \mathrm{~mm}$ and then a transition in hardness to $\sim 150-240$ was measured at $r \approx 2.5$ $3.5 \mathrm{~mm}$ followed by an exceptionally high hardness of $\mathrm{Hv} \approx 330$ at $r \approx 4.0-5.0 \mathrm{~mm}$. The highest hardness with $\mathrm{Hv} \approx 330$ at the disk edge after 20 turns is significantly higher than the highest value of $\mathrm{Hv} \approx 270$ observed in a similar Al-Mg disk processed by HPT for 10 turns [14,15]. After HPT and PDA, there was a slight reduction in hardness to $\mathrm{Hv} \approx 30$ in the central regions up to $r \approx 3.0 \mathrm{~mm}$ and a reduction to $\mathrm{Hv} \approx 220$ at the outer region of the disk at 
$r \approx 4.0-5.0 \mathrm{~mm}$. Concerning the decreased hardness after annealing, the hardness value is about two times higher than the high hardness of $\mathrm{Hv} \approx 110-120$ recorded at the Al-Mg disk edge after HPT for 5 turns [14-16].

\subsection{Microstructural and compositional analysis}

The results of the microstructural and compositional analyses are presented in Fig. 3 for the disk edge of the Al-Mg system after HPT for 20 turns where (a) and (b) show representative TEM bright-field images, (c) shows the corresponding diffraction ring patterns observed at the region depicted in (b), and (d) shows a dark-field image together with the corresponding compositional maps of (e) $\mathrm{Al}$ and (f) $\mathrm{Mg}$.

It is apparent that there is a mixture of the regions with a layered structure and an equiaxed microstructure as shown in Fig. 3(a) and (b), respectively, at the disk edge immediately after HPT for 20 turns. The layered microstructure has an average thickness of $\sim 20 \mathrm{~nm}$ and these layers contain numerous dislocations which subdivide the layers in a vertical sense. The equiaxed grains showed an average spatial grain size of $d \approx 60 \mathrm{~nm}$ and thus the microstructure was even finer than the value of $d \approx 90 \mathrm{~nm}$ measured in an $\mathrm{Al}-\mathrm{Mg}$ system after HPT for 10 turns [14]. The diffraction ring patterns in Fig. 3(c) provide a direct proof of the presence of an intermetallic compound of $\gamma-\mathrm{Al}_{12} \mathrm{Mg}_{17}$.

A compositional analysis was conducted in STEM mode in the region including the layered microstructure as shown in Fig. 3(a) and the results are given in Fig. 3(d)-(f) where the location for the point element analysis is denoted in Fig. 3(d) as Spectrum 1. It is apparent in the measurement window, and also in several additional measurements, that all of the measurement area is composed of both $\mathrm{Al}$ and $\mathrm{Mg}$ atoms and there is no $\mathrm{Mg}$-rich phase at the disk edge in the Al-Mg system after HPT for 20 turns. A point element analysis was conducted on a randomly selected thin layer having a thickness of $\sim 30 \mathrm{~nm}$ and the results gave concentrations of $\sim 57.55$ at. $\%$ of $\mathrm{Al}$ and $\sim 41.84$ at. $\%$ of $\mathrm{Mg}$, thereby indicating the 
selected thin layer consists of an intermetallic compound of $\beta-\mathrm{Al}_{3} \mathrm{Mg}_{2}$. Thus, the edge of the Al-Mg disk processed by HPT for 20 turns demonstrated the formation of an MMNC containing two intermetallic compounds of $\beta-\mathrm{Al}_{3} \mathrm{Mg}_{2}$ and $\gamma-\mathrm{Al}_{12} \mathrm{Mg}_{17}$ where the formation of these two intermetallic compounds was also observed after 10 turns in the same metal system [14].

A series of microstructural analyses was performed at the disk edge after HPT for 20 turns followed by PDA and the results are shown in Fig. 4 where a TEM bright-field image and a high-resolution image are shown in (a) and (b), respectively, and (c) shows a dark-field image and the corresponding compositional maps of (d) $\mathrm{Al}$ and (e) $\mathrm{Mg}$. It is apparent from Fig. 4(a) that after PDA the HPT-processed Al-Mg system contained a homogeneous equiaxed microstructure and the average grain size was measured as $d \approx 380 \mathrm{~nm}$. The highresolution TEM image in Fig. 4(b) demonstrates a grain with the measured lattice spacing of $\sim 0.236 \mathrm{~nm}$ which is estimated as an $\mathrm{Al}-7 \% \mathrm{Mg}$ solid solution [26]. This result is also observed in the compositional analysis shown in Fig. 4(c)-(e) where the point analyses were conducted for two locations of Spectrum 2 and 3. In practice, the point analyses detected concentrations of $\sim 59.02$ at.\% of $\mathrm{Al}$ and 40.04 at.\% of $\mathrm{Mg}$ for Spectrum 2 and 91.42 at.\% of $\mathrm{Al}$ and $~ 8.58$ at. $\%$ of $\mathrm{Mg}$ for Spectrum 3. Thus, these results demonstrate the presence of $\beta-\mathrm{Al}_{3} \mathrm{Mg}_{2}$ and $\mathrm{Al}-7 \% \mathrm{Mg}$ for Spectrums 2 and 3, respectively, where it should be noted that the actual $\mathrm{Mg}$ concentration in the $\mathrm{Al}$ solid solution tends to be higher than the nominal composition of Al-Mg alloy [27,28]. In addition, the disk edge after HPT and PDA revealed no Mg-rich phase and there was no evidence for a $\gamma-\mathrm{Al}_{12} \mathrm{Mg}_{17}$ intermetallic compound as observed at the disk edge after HPT without PDA.

The results of the X-ray analysis are shown in Fig. 5 where the X-ray profiles are given for the disk edges of the Al-Mg system after (a) 20 turns by HPT and (b) HPT and PDA, and further compositional analysis based on the X-ray profiles was conducted through 
MAUD and displayed as a Table in each plot. The X-ray analysis essentially confirmed the experimental results from the microstructural and chemical analysis. Thus, immediately after HPT for 20 turns there was evidence of $\gamma-\mathrm{Al}_{12} \mathrm{Mg}_{17}$ with a negligible amount of $\beta-\mathrm{Al}_{3} \mathrm{Mg}_{2}$ whereas after PDA there was an $\mathrm{Al}-7 \% \mathrm{Mg}$ solid solution phase with both $\beta-\mathrm{Al}_{3} \mathrm{Mg}_{2}$ and $\gamma-$ $\mathrm{Al}_{12} \mathrm{Mg}_{17}$. Therefore, it is established that processing by HPT for 20 turns and additional PDA produced two different types of MMNCs at the disk edges of the Al-Mg system.

It is important to note that the $\mathrm{Mg}$ contents detected in both samples are due to the inevitable concentrations of the Mg-rich phase that exist close to the mid-radius of the processed samples as seen in Fig. 2(a) whereas the X-ray measurements were conducted after removing the central region over a radius of $1.5 \mathrm{~mm}$.

\subsection{Micro-mechanical and tribological properties}

The plastic behavior of the MMNCs in the Al-Mg system was examined at RT using a nanoindentation facility after HPT for 20 turns and after HPT and PDA. Figure 6 shows representative load-displacement curves for the Al-Mg disk edges after (a) HPT for 20 turns and (b) HPT and PDA when measuring at four strain rates of $1.0 \times 10^{-3}-1.25 \times 10^{-4} \mathrm{~s}^{-1}$ under a predetermined maximum peak load of $50 \mathrm{mN}$. It should be noted that the discontinuities of the curves at the final stages of unloading are due to thermal expansion and these effects are omitted from the analysis.

The disk edge after HPT for 20 turns showed all four load-displacement curves placed in reasonably consistent locations as shown in Fig. 6(a). However, close inspection shows the occurrence of less displacement when the strain rate is slower, thereby indicating a negative dependency of plasticity on strain rate. By contrast, the MMNC processed by HPT followed by PDA revealed an apparent positive strain rate dependency where increasing displacements were achieved at slower strain rates of nanoindentation as shown in Fig. 6(b). It is also apparent from Fig. 6 that the MMNC immediately after HPT shows much lower 
displacements than the MMNC after HPT and PDA at all strain rates, thereby demonstrating the high hardness of the MMNC in the Al-Mg disk edge immediately after HPT for 20 turns. This result is fully consistent with the hardness mapping shown in Fig. 2(b).

It should be noted also that there was no evidence for any plastic instability in both MMNCs at the disk edges after HPT for 20 turns and after PDA whereas a plastic instability was observed earlier in an Al-Mg system after HPT for 5 turns [16]. This apparent dichotomy is probably due to the higher volume fractions and the homogeneous distributions of the hard and fine phases of the intermetallic compounds within the matrix after higher numbers of HPT turns as in the present study.

Small-scale sliding tests were conducted under a load of $3 \mathrm{~N}$ on the disk edges consisting of MMNCs in the Al-Mg system after HPT for 20 turns and after HPT followed by PDA and a plot of the friction coefficient versus the total sliding distance is shown in Fig. 7 for these two disk edges. There are two significant features in Fig. 7. First, the coefficients of friction increase slightly in the early stages of the sliding tests up to sliding lengths of $\sim 500$ $\mathrm{cm}$ and thereafter they are reasonably saturated up to total sliding distances of $2000 \mathrm{~cm}$ in both materials. Second, the MMNC in the Al-Mg disk edge immediately after HPT shows lower sliding coefficients throughout the tests by comparison with the MMNC after HPT and PDA. In practice, the coefficients in the initial states of sliding are $\sim 0.30$ and $\sim 0.37$ and these increase to $\sim 0.37$ and $\sim 0.48$ in the steady-state condition for the disk edge after HPT and after HPT and PDA, respectively.

For comparison purposes, the sliding tests were also conducted under the same sliding conditions on separate disks of the Al-1050 and ZK60 magnesium alloys after HPT for 10 turns where this number of HPT turns provides a reasonable saturation in microstructure $[29,30]$. The recorded friction coefficients at the initial state and in the steady-state conditions 
are listed in Table 1 for the Al-Mg system after HPT, HPT and PDA and in the separate Al1050 and ZK60 disks after HPT.

Although the present testing used a low sliding load of $3 \mathrm{~N}$, separate $\mathrm{Al}$ disks tested after HPT showed consistent values of the friction coefficient of $\sim 0.60$ under a sliding load of $23 \mathrm{~N}$ for an Al-1050 alloy after HPT for 5 turns under $6.0 \mathrm{GPa}$ at RT [31] and $\sim 0.55-0.66$ under a sliding load of 5-23N for an Al-1050 alloy after ECAP for 8 passes [32]. Similarly, the friction coefficient of the ZK60 alloy is consistent with $\sim 0.25-0.8$ under a sliding load of 10-50N for an AZ91 alloy after ECAP for 2 passes [33] and 0.26-0.29 under a sliding load of 5-25N for an AZ31 alloy after ECAP for 8 passes [34]. It is interesting to note that both AlMg systems processed in the present study showed lower values of the friction coefficient than the HPT-processed Al whereas the values were simile and slightly higher than the $\mathrm{Mg}$ alloy after HPT for 10 turns.

Figure 8 shows the three-dimensional depth-sensing photos at vertical sections in the middle of the wear tracks (left) and SEM micrographs of the worn surfaces (right) for (a) and (b) an MMNC at the disk edge in the Al-Mg system after HPT for 20 turns and (c) and (d) an MMNC at the disk edge after HPT and PDA. The detailed depth information is denoted by the color key beside each depth sensing plot. The processed Al-Mg system prior to PDA exhibited much less wear track volume compared with the HPT-processed sample followed by PDA. However, both samples showed wear debris especially at the end of the sliding tracks as shown in Fig. 8(b) and (d), thus demonstrating an adhesive wear behavior in both MMNCs in the Al-Mg system. This type of wear behavior was also demonstrated in an Al$\mathrm{Al}_{2} \mathrm{O}_{3}$ composite from powder-consolidated by HPT for up to 10 turns [35].

\section{Discussion}

\subsection{The improvement in micro-mechanical response by PDA}


The deformation characteristics at RT were evaluated by calculating the strain rate sensitivity, $m$, from the data set of nanoindentation testing shown in Fig. 6. Considering Tabor's empirical prediction where the flow stress is equivalent to $H / 3$ for fully plastic deformation at a constant strain rate, $\dot{\varepsilon}$ [36], where $H$ is the nanoindentation hardness estimated according to the Oliver-Pharr method [37], the value of $m$ was determined using the measured hardness value at a given strain, $\varepsilon$, and absolute temperature, $T$, by the expression [38]:

$$
m=\left(\frac{\partial \ln \sigma_{f}}{\partial \ln \dot{\varepsilon}}\right)_{\varepsilon, T}=\left(\frac{\partial \ln (H / 3)}{\partial \ln \dot{\varepsilon}}\right)_{\varepsilon, T}
$$

Thus, the values of $m$ were calculated from the slopes of the lines in a logarithmic plot of $H / 3$ against $\dot{\varepsilon}$ as shown in Fig. 9 for the disk edges of the Al-Mg system after HPT for 20 turns and after HPT and PDA at $573 \mathrm{k}$ for 1 hour.

The analysis estimated $m$ values of -0.001 and 0.1 for the MMNCs after HPT and HPT followed by PDA, respectively, as shown in Fig. 9. The negative value of $m$ in the AlMg system after HPT for 20 turns is apparently smaller than $m<0.01$ at the disk edge of the metal system after HPT for 5 turns where the sample exhibited wider error bars due to plastic instability especially with increasing indentation strain rates [16]. Accordingly, the PDA treatment provided a significant enhancement in the $m$ value of the $\mathrm{MMNC}$ in the $\mathrm{Al}-\mathrm{Mg}$ system processed by HPT.

It should be noted that the improved $m$ value of 0.1 for the $\mathrm{MMNC}$ in the $\mathrm{Al}-\mathrm{Mg}$ system after HPT and PDA is even higher than earlier reports where $m$ values were estimated through nanoindentation testing of $\sim 0.07$ for a commercial purity $\mathrm{Al}$ after ECAP for $6-12$ passes at RT [39-42] and after ARB for 8 cycles at RT [40] and $~ 0.035-0.050$ for a ZK60 alloy after HPT for 2 turns at RT [43]. Thus, the MMNC after HPT followed by PDA demonstrates a significantly higher value of $m$ compared with the initial materials when they are processed separately. 
It is now well established that there is generally a significant loss in ductility in bulk materials having UFG microstructures where a marked increase in hardness and strength is achieved by grain refinement through SPD [44-47]. Specifically, the lower overall ductility in the UFG materials is generally attributed to an interrelationship between the lower strain hardening and an increasing strain rate sensitivity $[48,49]$. Nevertheless, the present nanoindentation analysis shows that there is a significant increase in the strain rate sensitivity in the Al-Mg system after HPT and PDA. Thus, a PDA treatment is feasible for enhancing the RT plasticity of the MMNC in the Al-Mg system after HPT while maintaining reasonably high hardness as shown in Figs 2(b) and 6(b).

The significance of PDA was demonstrated earlier for improving the overall ductility of nanostructured Ti after HPT [50]. As reviewed recently [47], this approach produces an ordering of the defect structures within the grain boundaries leading to an equilibrium state without any significant grain growth. In addition, short-term annealing reduces the dislocation density in the grain interior of the UFG material after SPD so that the dislocation storage capability may increase and thus the strain hardening capability is enhanced wand this leads to the possibility of high ductility in the SPD-processed material. There are several recent reports demonstrating the significance of PDA on mechanical properties at RT of HPT-processed materials [51-54]. Thus, considering the present nanoindentation results reporting a significant enhancement in the strain rate sensitivity after PDA, the MMNC in the Al-Mg system produced by HPT has a great potential for demonstrating both high hardness and superior ductility.

There are several reports showing negative strain rate sensitivities in nanostructured metals of Ti after ECAP followed by cold rolling [55] and Al alloys produced through cryomilling [56,57]. The consistent behavior of these metals involves a strain-rate dependent instability of plasticity attributed to the occurrence of dynamic strain aging (DSA) leading to 
the local formation of solute clusters on forest dislocations resulting in a strengthening of dislocation junctions [58]. A very limited report of a negative strain rate sensitivity was documented in an MMNC of a powder consolidated aluminum $6092 / \mathrm{B}_{4} \mathrm{C}$ when testing at strain rates of $<1.0 \mathrm{~s}^{-1}$ [59] and the report attributed the occurrence of DSA to the fast diffusion of solute atoms which interacted with mobile dislocations. Thus, for the MMNC in the Al-Mg system immediately after HPT for 20 turns, the decreasing plasticity demonstrated by the reduced strain rates is reasonable because of the interaction of a significant number of dislocations introduced during HPT with the very rapid Mg solutes within the Al matrix. The rapid diffusivity of $\mathrm{Mg}$ atoms is a key process for the diffusion bonding of $\mathrm{Al}$ and $\mathrm{Mg}$ in producing the Al-Mg system though HPT [14,15] and a recent review described the acceptance of the fast atomic mobility during SPD by recognizing the significant increase in the vacancy concentration through SPD processing [60].

\subsection{Wear resistance in the MMNCs of the Al-Mg system}

The morphology of the wear scars in Fig. 8 demonstrates that the wear depth in the HPT-processed MMNC is increased by about two times after the PDA treatment whereas the wear width was reasonably consistent under the present testing conditions. The volume loss during sliding wear is expected to be higher in the PDA-treated MMNC than immediately after HPT, thereby demonstrating a reduction in wear resistivity.

These tribology results were further analyzed quantitatively for a better understanding of the wear properties in these MMNCs in the Al-Mg system after HPT and with the additional PDA treatment. The specific wear rate, $k$, is widely applied for estimating the wear properties by direct comparison between the different classes of materials and this dimensional wear rate is defined by:

$$
k=\frac{V}{P L}=\frac{W}{P L \rho}
$$


where $V$ is the wear volume, $P$ is the normal load, $L$ is the sliding distance, $W$ is the weightloss and $\rho$ is the density of the material. The $k$ value is a normalized parameter of the wear coefficient defined by Archard's equation [61] for the hardness of materials and thus materials with higher hardness have lower $k$ values where this indicates better wear resistance.

Table 2 shows the measured weight loss, density, wear volume and the specific wear rate estimated by applying eq (2) with the experimental conditions of $P=3 \mathrm{~N}$ and $L=20 \mathrm{~m}$ for the MMNCs in the Al-Mg system after HPT for 20 turns and after HPT and PDA: the two lower rows show the same data for the initial materials of the Al-1050 and ZK60 magnesium alloys processed by HPT for 10 turns. It should be noted that the density for the MMNCs was carefully measured only at the disk edges in the Al-Mg system and both MMNCs showed the same density of $\sim 2.34 \mathrm{~g} / \mathrm{cm}^{3}$ which is even lower than $\sim 2.48 \mathrm{~g} / \mathrm{cm}^{3}$ as measured in the Al-Mg system after HPT for 10 turns [14].

It is apparent from Table 2 that the MMNC in the Al-Mg system after HPT for 20 turns demonstrates a lower $k$ value than the PDA-treated MMNC in the Al-Mg system and it is significantly lower compared with the separate $\mathrm{Al}$ and $\mathrm{Mg}$ alloys processed by HPT. Thus, processing through HPT for 20 turns demonstrates a great potential for producing an MMNC in the Al-Mg system with a significantly high wear resistance. This result is anticipated by the general correlation between hardness and wear [62]. Similar values of the friction coefficient of $\sim 0.30$ and the specific wear rate of $\sim 0.003 \mathrm{~mm}^{3} / \mathrm{Nm}$ were estimated in an MA60- $\mathrm{Al}_{2} \mathrm{O}_{3}$ magnesium matrix composite processed by ECAP for 4 passes at $573 \mathrm{~K}$ [63].

It should be noted that, although the $k$ value was increased after PDA, the specific wear rate in the MMNC after HPT and PDA was lower than the separate Al and Mg alloys after HPT. The ability to maintain a reasonable wear resistivity is due to the improved strain hardening capability as suggested in the present nanoindentation results for the MMNC after PDA. As was noted earlier [62], the loss in strain hardening capability has a negative 
influence on the wear resistance. Furthermore, a reduced wear resistance after SPD was demonstrated in a commercial purity $\mathrm{Al}$ after ECAP [32] and after HPT [31] and in several $\mathrm{Al}$ alloys after ARB [64-67]. In practice, strain hardening is not the only parameter but rather there are also a number of physical parameters and mechanisms that contribute to the wear properties of materials.

\subsection{An alternative strategy for synthesizing new materials though HPT}

Attempts to improve the mechanical properties by grain refinement have been one of the main objectives for the application of SPD to bulk metals. As reviewed recently [68], extensive research over the last decade has demonstrated that SPD processing is also feasible in the production of unusual phase transformations and in the introduction of a range of nanostructural features. These recent developments include the alternative method of using HPT for introducing high performance materials through bonding dissimilar metals by synthesizing new metal systems and ultimately producing MMNCs as shown in the present report. It should be emphasized that the MMNCs synthesized at the disk edges of the Al-Mg system receive very high straining through HPT in the present study but the final bulk metal contains a gradient-type microstructure [23-25] or a heterogeneous nanostructure [69] according to grain size and composition $[14,70]$. Although this type of microstructure is wellknown in many biological systems [71], it is a new category of structure in engineering materials and it is expected to lead to a significant potential for exhibiting excellent mechanical properties.

It is worthwhile noting that the exceptional hardness of $\mathrm{Hv} \approx 330$ achieved for the MMNC at the Al-Mg disk edge immediately after HPT is equivalent to $1060 \mathrm{MPa}$ in tensile strength. This high strength leads to an excellent strength/weight ratio of $\sim 455 \mathrm{MPa} \mathrm{cm}{ }^{3} \mathrm{~g}^{-1}$ under a measured density of $2.34 \mathrm{~g} \mathrm{~cm}^{-3}$ as shown in Table 2 for the MMNC processed by

HPT for 20 turns. This value is much higher than $\sim 350 \mathrm{MPa} \mathrm{cm}^{3} \mathrm{~g}^{-1}$ for another type of 
MMNC in the Al-Mg system after HPT for 10 turns [14,15], thereby demonstrating the further enhancement in the specific strength of the Al-Mg system when processing by HPT with increasing numbers of turns.

In a recent report, newly developed structural materials having a new scale of materials organization are defined as heterogeneous architecture materials where the development of these materials may often require new processing methods [72]. In practice, however, the present experiments used a conventional HPT facility and there was the successful formation of an MMNC in the Al-Mg system through HPT processing for 20 turns at RT. The synthesized MMNC after HPT demonstrated exceptional hardness, excellent wear resistance and a superior strength/weight ratio. Moreover, an additional PDA treatment provided enhanced plasticity while reasonably maintaining the wear resistivity by producing a different type of MMNC in the system. These results demonstrate a considerable potential for applying HPT processing for the synthesis of new alloy systems, especially by simply and expeditiously fabricating a wide range of MMNCs from simple metals and alloys and by incorporating an additional treatment of PDA to further improve the mechanical properties of the HPT-processed materials.

\section{Summary and conclusions}

1. The synthesis of an MMNC in an Al-Mg system was demonstrated using conventional HPT processing for 20 turns at room temperature through the diffusion bonding of separate $\mathrm{Al}$ and $\mathrm{Mg}$ disks. Following processing, PDA was conducted at $573 \mathrm{~K}$ for 1 hour. The deformed microstructure and micro-mechanical and tribological properties were examined to evaluate the feasibility of using HPT for the formation of an MMNC with excellent mechanical properties and the significance of applying PDA for the improvement and enhancement of properties including plasticity and wear resistance. 
2. The results demonstrate the formation of two intermetallic compounds of $\beta-\mathrm{Al}_{3} \mathrm{Mg}_{2}$ in the form of thin layers and $\gamma-\mathrm{Al}_{12} \mathrm{Mg}_{17}$ in parts of the matrix at the disk edge leading to the synthesis of MMNC with a grain size of $\sim 60 \mathrm{~nm}$ in the Al-Mg system after HPT for 20 turns. After PDA, the synthesized MMNC recovered to have an equiaxed microstructure with a grain size of $\sim 380 \mathrm{~nm}$ and forming a different type of MMNC with only one intermetallic compound of $\beta-\mathrm{Al}_{3} \mathrm{Mg}_{2}$ and a phase of an $\mathrm{Al}-7 \% \mathrm{Mg}$ solid solution.

3. The microstructural evolution provided exceptional Vickers microhardness of $\sim 330$ in the MMNC immediately after HPT whereas it was reduced to 220 after PDA. Nanoindentation analysis demonstrated mechanical characteristics involving a negative strain rate sensitivity of -0.001 in the MMNC processed immediately after HPT. The plastic behavior was improved significantly to show $m \approx 0.1$ after PDA.

4. Small-scale sliding tests showed a very low specific wear rate of $\sim 0.005$ for the MMNC immediately after HPT, thereby demonstrating excellent wear resistance of the MMNC in the Al-Mg system. After PDA, the wear resistivity was reasonably maintained without significant loss due to an increase in the strain hardening capability of the MMNC after the PDA treatment.

5. The results demonstrated a considerable potential for using conventional HPT processing for the development of new alloy systems and for the formation of MMNCs. In addition, the desirable mechanical properties can be further enhanced by applying PDA. 


\section{Acknowledgements}

This work was supported by the NRF Korea funded by MoE under Grant No. NRF2014R1A1A2057697 and NRF-2016R1A6A1A03013422, and by MSIP under Grant No. NRF-2016K1A4A3914691 (MK); the NRF Korea funded by MSIP under Grant No. NRF2015R1A5A1037627 (JIJ); and the European Research Council under ERC Grant Agreement No. 267464-SPDMETALS (TGL). 


\section{References}

[1] K. Lu, The future of metals, Science 328 (2010) 319-320.

[2] P.V. Liddicoat, X.Z. Liao, Y.T. Zhu, Y.H. Zhao, E.J. Lavernia, M.Y. Murashkin, R.Z. Valiev, S.P. Ringer, New hierarchy of solute architecture breaks strength ceiling in a nanocrystalline aluminium alloy, Nature Commun. 1 (2010) 63/1-7.

[3] R.Z. Valiev, R.K. Islamgaliev, I.V. Alexandrov, Bulk nanostructured materials from severe plastic deformation, Prog. Mater. Sci. 45 (2000) 103-189.

[4] A.P. Zhilyaev, T.G. Langdon, Using high-pressure torsion for metal processing: Fundamentals and applications, Prog. Mater. Sci. 53 (2008) 893-979.

[5] T.G. Langdon, Twenty-five years of ultrafine-grained materials: Achieving exceptional properties through grain refinement, Acta Mater. 61 (2013) 7035-7059.

[6] A.P. Zhilyaev, A.A. Gimazov, G.I. Raab, T.G. Langdon, Using high-pressure torsion for the cold-consolidation of copper chips produced by machining, Mater. Sci. Eng. A 486 (2008) 123-126.

[7] A.V. Korznikov, I.M. Safarov, D.V. Laptionok, R.Z. Valiev, Structure and properties of superfine-grained iron compacted out of ultradisperse powder, Acta Metall. Mater. 39 (1991) 3193-3197.

[8] K.V. Rajulapati, R.O. Scattergood, K.L. Murty, Z. Horita, T.G. Langdon, C.C. Koch, Mechanical properties of bulk nanocrystalline aluminum-tungsten alloys, Metall. Mater. Trans. A 39A (2008) 2528-2534.

[9] K. Edalati, S. Toh, H. Iwaoka, Z. Horita, Microstructural characteristics of tungstenbase nanocomposites produced from micropowders by high-pressure torsion, Acta Mater. 60 (2012) 3885-3893.

[10] S. Sabbaghianrad, T. G. Langdon, A critical evaluation of the processing of an aluminum 7075 alloy using a combination of ECAP and HPT, Mater. Sci. Eng. A 596 (2014) 52-58.

[11] K. Oh-ishi, K. Edalati, H.S. Kim, K. Hono, Z. Horita, High-pressure torsion for enhanced atomic diffusion and promoting solid-state reactions in the aluminumcopper system, Acta Mater. 61 (2013) 3482-3489.

[12] O. Bouaziz, H.S. Kim, Y. Estrin, Architecturing of metal-based composites with concurrent nanostructuring: A new paradigm of materials design, Adv. Eng. Mater. 15 (2013) 336-340.

[13] X. Qiao, X. Li, X. Zhang, Y. Chen, M. Zheng, I.S. Golovin, N. Gao, M.J. Starink, Intermetallics formed at interface of ultrafine grained $\mathrm{Al} / \mathrm{Mg}$ bi-layered disks processed by high pressure torsion at room temperature, Mater. Lett. 181 (2016) 187190. 
[14] B. Ahn, A.P. Zhilyaev, H.-J. Lee, M. Kawasaki, T.G. Langdon, Rapid synthesis of an extra hard metal matrix nanocomposite at ambient temperature, Mater. Sci. Eng. A 635 (2015) 109-117.

[15] M. Kawasaki, B. Ahn, H.-J. Lee, A.P. Zhilyaev, T.G. Langdon, Using high-pressure torsion to process an aluminum-magnesium nanocomposite through diffusion bonding, J. Mater. Res. 31 (2016) 88-99.

[16] B. Ahn, H.-J. Lee, I.C. Choi, M. Kawasaki, J.-I. Jang, T.G. Langdon, Micromechanical behavior of an exceptionally strong metal matrix nanocomposite processed by high-pressure torsion, Adv. Eng. Mater. 18 (2016) 1001-1008.

[17] R.B. Figueiredo, P.R. Cetlin, T.G. Langdon, Using finite element modeling to examine the flow processes in quasi-constrained high-pressure torsion, Mater. Sci. Eng. A 528 (2011) 8198-8204.

[18] R.B. Figueiredo, P.H.R. Pereira, M.T.P. Aguilar, P.R. Cetlin, T.G. Langdon, Using finite element modeling to examine the temperature distribution in quasi-constrained high-pressure torsion, Acta Mater. 60 (2012) 3190-3198.

[19] M. Kawasaki, T.G. Langdon, The significance of strain reversals during processing by high-pressure torsion, Mater. Sci. Eng. A 498 (2008) 341-348.

[20] R.Z. Valiev, Yu.V. Ivanisenko, E.F. Rauch, B. Baudelet, Structure and deformaton behaviour of Armco iron subjected to severe plastic deformation, Acta Mater. 44 (1996) 4705-4712.

[21] F. Wetscher, A. Vorhauer, R. Stock, R. Pippan, Structural refinement of low alloyed steels during severe plastic deformation, Mater. Sci. Eng. A387-389 (2004) 809-816.

[22] F. Wetscher, R. Pippan, S. Sturm, F. Kauffmann, C. Scheu, G. Dehm, TEM investigations of the structural evolution in a pearlitic steel deformed by high-pressure torsion, Metall. Mater. Trans. A 37A (2006) 1963-1968.

[23] T.H. Fang, W.L. Li, N.R. Tao, K. Lu, Revealing extraordinary intrinsic tensile plasticity in gradient nano-grained copper, Science 331 (2011) 1587-1590.

[24] X. Wu, P. Jiang, L. Chen, F. Yuan, Y.T. Zhu, Extraordinary strain hardening by gradient structure, Proc. Natl. Acad. Sci. 111 (2014) 7197-7201.

[25] K. Lu, Making strong nanomaterials ductile with gradients, Science 345 (2014) 1455 1456.

[26] M. Schoenitz, E.L. Dreizin, Structure and properties of Al-Mg mechanical alloys, J. Mater. Res. 18 (2003) 1827-1836.

[27] X. Sauvage, N. Enikeev, R. Valiev, Y. Nasedkina, M. Murashkin, Atomic-scale analysis of the segregation and precipitation mechanisms in a severely deformed AlMg alloy, Acta Mater. 72 (2014) 125-136. 
[28] H.-J. Lee, J.-K. Han, S. Janakiraman, B. Ahn, M. Kawasaki, T.G. Langdon, Significance of grain refinement on microstructure and mechanical properties of an $\mathrm{Al}-3 \% \mathrm{Mg}$ alloy processed by high-pressure torsion, J. Alloys Compds 686 (2016) 998-1007.

[29] A.P. Zhilyaev, G.V. Nurislamova, B.-K. Kim, M.D. Baro, J.A. Szpunar, T.G. Langdon, Experimental parameters influencing grain refinement and microstructural evolution during high-pressure torsion, Acta Mater. 51 (2003) 753-765.

[30] A.P. Zhilyaev, S. Lee, G.V. Nurislamova, R.Z. Valiev, T.G. Langdon, Microhardness and microstructural evolution in pure nickel during high-pressure torsion, Scripta Mater. 44 (2001) 2753-2758.

[31] C.T. Wang, N. Gao, R.J.K. Wood, T.G. Langdon, Wear behaviour of Al-1050 alloy processed by severe plastic deformation, Mater. Sci. Forum 667-669 (2011) 11011106.

[32] C.T. Wang, N. Gao, R.J.K. Wood, T.G. Langdon, Wear behavior of an aluminum alloy processed by equal-channel angular pressing, J. Mater. Sci. 46 (2011) 123-130.

[33] V.I. Semenov, Y.-R. Jeng, S.-J. Huang, Y.-Zh. Dao, S.-J. Hwang, L.Sh. Shuster, S.V. Chertovskikh, P.-Ch. Lin, Tribological properties of the AZ91D magnesium alloy hardened with silicon carbide and by severe plastic deformation, J. Frict. Wear 30 (2009) 194-198.

[34] J. Xu, X. Wang, X. Zhu, M. Shirooyeh, J. Wongsa-Ngam, D. Shan, B. Guo, T.G. Langdon, Dry sliding wear of an AZ31 magnesium alloy processed by equal-channel angular pressing, J. Mater. Sci. 48 (2013) 4117-4127.

[35] K. Edalati, M. Ashida, Z. Horita, T. Matsui, H. Kato, Wear resistance and tribological features of pure aluminum and $\mathrm{Al}-\mathrm{Al}_{2} \mathrm{O}_{3}$ composites consolidated by high-pressure torsion, Wear 310 (2014) 83-89.

[36] S. Shim, J.-I. Jang, G.M. Pharr, Extraction of flow properties of single-crystal silicon carbide by nanoindentation and finite-element simulation, Acta Mater. 56 (2008) 3824-3832.

[37] W.C. Oliver, G.M. Pharr, An improved technique for determining hardness and elastic modulus using load and displacement sensing indentation experiments, J. Mater. Res. 7 (1992) 1564-1583.

[38] I.-C. Choi, Y.-J. Kim, Y.M. Wang, U. Ramamurty, J.-I. Jang, Nanoindentation behavior of nanotwinned $\mathrm{Cu}$ : Influence of indenter angle on hardness, strain rate sensitivity and activation volume, Acta Mater. 61 (2013) 7313-7323.

[39] J. Mueller, K. Durst, D. Amberger, M. Göken, Local investigations of the mechanical properties of ultrafine grained metals by nanoindentations, Mater. Sci. Forum 503-504 (2006) 31-36. 
[40] A. Böhner, V. Maier, K. Durst, H.W. Höppel. M. Göken, Macro- and nanomechanical properties and strain-rate sensitivity of accumulative roll bonded and equal channel angular pressed ultrafine-grained materials, Adv. Eng. Mater. 13 (2011) 251-255.

[41] V. Maier, B. Merle, M. Göken, K. Durst, An improved long-term nanoindentation creep testing approach for studying the local deformation processes in nanocrystalline metals at room and elevated temperatures, J. Mater. Res. 28 (2013) 1177-1188.

[42] J.M. Wheeler, V. Maier, K. Durst, M. Göken, J. Michler, Activation parameters for deformation of ultrafine-grained aluminium as determined by indentation strain rate jumps at elevated temperature, Mater. Sci. Eng. A 585 (2013) 108-113.

[43] I.-C. Choi, D.-H. Lee, B. Ahn, K. Durst, M. Kawasaki, T.G. Langdon, J.-I. Jang, Enhancement of strain-rate sensitivity and shear yield strength of a magnesium alloy processed by high-pressure torsion, Scripta Mater. 94 (2015) 44-47.

[44] R.Z. Valiev, I.V. Alexandrov, Y.T. Zhu, T.C. Lowe, Paradox of strength and ductility in metals processed by severe plastic deformation, J. Mater. Res. 17 (2002) 5-8.

[45] R. Valiev, Materials science: Nanomaterial advantage, Nature 419 (2002) 887-889.

[46] R. Valiev, Nanostructuring of metals by severe plastic deformation for advanced properties, Nat. Mater. 3 (2004) 511-516.

[47] P. Kumar, M. Kawasaki, T.G. Langdon, Review: Overcoming the paradox of strength and ductility in ultrafine-grained materials at low temperatures, J. Mater. Sci. 51 (2016) 7-18.

[48] Y.T. Zhu, X.Z. Liao, Nanostructured metals: Retaining ductility, Nat. Mater. 3 (2004) 351-352.

[49] R.Z. Valiev, Y. Estrin, Z. Horita, T.G. Langdon, M.J. Zehetbauer, Y.T. Zhu, Fundamentals of superior properties in bulk NanoSPD Materials, Mater. Res. Lett. 4 (2016) 1-21.

[50] R.Z. Valiev, A.V. Sergueeva, A.K. Mukherjee, The effect of annealing on tensile deformation behavior of nanostructured SPD titanium, Scripta Mater. 49 (2003) 669674.

[51] O. Andreau, J. Gubicza, N.X. Zhang, Y. Huang, P. Jenei, T.G. Langdon, Effect of short-term annealing on the microstructures and flow properties of an $\mathrm{Al}-1 \% \mathrm{Mg}$ alloy processed by high-pressure torsion, Mater. Sci. Eng. A 615 (2014) 231-239.

[52] N. Maury, N.X. Zhang, Y. Huang, A.P. Zhilyaev, T.G. Langdon, A critical examination of pure tantalum processed by high-pressure torsion, Mater. Sci. Eng. A 638 (2015) 174-182. 
[53] Y. Huang, M. Lemang, N.X. Zhang, P.H.R. Pereira, T.G. Langdon, Achieving superior grain refinement and mechanical properties in vanadium through highpressure torsion and subsequent short-term annealing, Mater. Sci. Eng. A 655 (2016) 60-69.

[54] H. Shahmir, J. He, Z. Lu, M. Kawasaki, T.G. Langdon, Effect of annealing on mechanical properties of a nanocrystalline CoCrFeNiMn high-entropy alloy processed by high-pressure torsion, Mater. Sci. Eng. A 676 (2016) 294-303.

[55] D. Jia, Y.M. Wang, K.T. Ramesh, E. Ma, Y.T. Zhu, R.Z. Valiev, Deformation behavior and plastic instabilities of ultrafine-grained titanium, Appl. Phys. Lett. 79 (2001) 611-613.

[56] B.Q. Han, Z. Lee, S.R. Nutt, E.J. Lavernia, F.A. Mohamed, Mechanical properties of an ultrafine-grained Al-7.5 pct Mg alloy, Metall. Mater. Trans. A 34A (2003) 603-613.

[57] B.Q. Han, J. Huang, Y.T. Zhu, E.J. Lavernia, Negative strain-rate sensitivity in a nanostructured aluminum alloy, Adv. Eng. Mater. 8 (2006) 945-947.

[58] R.C. Picu, A mechanism for the negative strain-rate sensitivity of dilute solid solutions, Acta Mater. 52 (2004) 3447-3458.

[59] H. Zhang, K.T. Ramesh, E.S.C. Chin, High strain rate response of aluminum 6092/B 4 C composites, Mater. Sci. Eng. A 384 (2004) 26-34.

[60] X. Sauvage, G. Wilde, S.V. Divinski, Z. Horita, R.Z. Valiev, Grain boundaries in ultrafine grained materials processed by severe plastic deformation and related phenomena, Mater. Sci. Eng. A 540 (2012) 1-12.

[61] J.F. Archard, Contact and rubbing of flat surfaces, J. Appl. Phys. 24 (1953) 981-988.

[62] N. Gao, C.T. Wang, R.J.K. Wood, T.G. Langdon, Tribological properties of ultrafinegrained materials processed by severe plastic deformation, J. Mater. Sci. 47 (2012) 4779-4797.

[63] S.-J. Huang, P.-C. Lin, B. Ballóková, P. Hvizdoš, M. Besterci, Tribological behavior and local mechanical properties of magnesium alumina composites, Kovove. Mater. 52 (2014) 313-319.

[64] Y.S. Kim, J.S. Ha, W.J. Kim, Dry sliding wear characteristics of severely deformed 6061 aluminum and AZ61 magnesium alloys, Mater. Sci. Forum 449-452 (2004) 597600.

[65] Y.S. Kim, T.O. Lee, D.H Shin, Microstructural evolution and mechanical properties of ultrafine grained commercially pure 1100 aluminum alloy processed by accumulative roll-bonding (ARB), Mater. Sci. Forum 449-452 (2004) 625-628.

[66] Y.S. Kim, J.S. Ha, D.H. Shin, Sliding wear characteristics of ultrafine-grained nonstrain-hardening aluminum-magnesium alloys, Mater. Sci. Forum 475-479 (2005) 401-404. 
[67] M. Eizadjou, A.K. Talachi, H.D. Manesh, K. Janghorban, Sliding wear behavior of severely deformed 6061 aluminum alloy by accumulative roll bonding (ARB) process, Mater. Sci. Forum 667-669 (2011) 1107-1112.

[68] R.Z. Valiev, Y. Estrin, Z. Horita, T.G. Langdon, M.J. Zehetbauer, Y. Zhu, Producing bulk ultrafine-grained materials by severe plastic deformation: Ten years later, JOM 68 (2016) 1216-1226.

[69] X.L. Wu, P. Jiang, L. Chen, J.F. Zhang, F.P. Yuan, Y.T. Zhu, Synergetic strengthening by gradient structure, Mater. Res. Lett. 2 (2014) 185-191.

[70] J.Y. Kang, J.G. Kim, H.W. Park, H.S. Kim, Multiscale architectured materials with composition and grain size gradients manufactured using high-pressure torsion, Sci. Rep. 6 (2016) 26590/1-10.

[71] P.-Y. Chen, J. McKittrick, M.A. Meyers, Biological materials: Functional adaptations and bioinspired designs, Prog. Mater. Sci. 57 (2012) 1492-1704.

[72] O. Bouaziz, Y. Bréchet, J.D. Embury, Heterogeneous and architectured materials: A possible strategy for design of structural materials, Adv. Eng. Mater. 10 (2008) 24-36. 


\section{Figure captions}

Fig. 1 Schematic illustration showing the locations of small-scale sliding tests in an HPT disk.

Fig. 2 (a) The OM micrographs of the Al-Mg disks after HPT at room temperature under a pressure of $6.0 \mathrm{GPa}$ and (b) color-coded contour maps of the Vickers microhardness for the vertical cross-sectional planes after HPT for 20 turns (upper) and after HPT and PDA (lower), respectively.

Fig. 3 (a) and (b) Representative TEM bright-field images, (c) the corresponding diffraction ring patters observed at the microstructural region showing in (b), and (d) a darkfield image together with the corresponding compositional maps of (e) $\mathrm{Al}$ and (f) $\mathrm{Mg}$ for the disk edge in the Al-Mg system after HPT for 20 turns.

Fig. 4 (a) A representative TEM bright-field image and (b) a high-resolution TEM image, and (c) a dark-field image together with the corresponding compositional maps of (d) $\mathrm{Al}$ and (e) Mg taken at the disk edge after HPT for 20 turns followed by PDA.

Fig. 5 X-ray profiles for the disk edges of the Al-Mg system after (a) HPT for 20 turns and (b) HPT and PDA: additional compositional analysis based on the X-ray profile through MOUD was displayed as a table in each plot.

Fig. 6 Representative load-displacement curves for the Al-Mg disk edges after (a) HPT for 20 turns and (b) HPT and PDA when measuring at four strain rates at $1.0 \times 10^{-3}$ $1.25 \times 10^{-4} \mathrm{~s}^{-1}$ under a predetermined maximum peak load of $50 \mathrm{mN}$.

Fig. 7 Plots of the friction coefficient with increasing the total sliding distance under the load of $3 \mathrm{~N}$ on the disk edges consisting of MMNCs in the Al-Mg system after HPT for 20 turns and after HPT and PDA.

Fig. 8 Three-dimensional depth-sensing photos at the vertical sections in the middle of the wear tracks (left) and the SEM micrographs of the worn surfaces (right) for (a) and (b) the NNMC at the disk edge in the Al-Mg system after HPT for 20 turns and (c) and (d) another type of NNMC at the disk edge after HPT and PDA: the detailed depth information is denoted by the color key beside each depth-sensing plot.

Fig. 9 Variations of the strain rate sensitivity with increasing strain rate for the disk edges of the Al-Mg system after HPT for 20 turns and after HPT and PDA. 


\section{Table captions}

Table 1. The recorded friction coefficients at the initial stage and the steady-state condition for the Al-Mg system after HPT and HPT and PDA and for the Al and Mg alloy disks after HPT.

Table 2. The measured weight loss, density, wear volume and the estimated specific wear rate at $P=3 \mathrm{~N}$ and $L=20 \mathrm{~m}$ for the MMNCs in the Al-Mg system after HPT for 20 turns and after HPT and PDA and for the initial Al-1050 and ZK60 alloys after HPT for 10 turns. 
Figure 1

Click here to download high resolution image

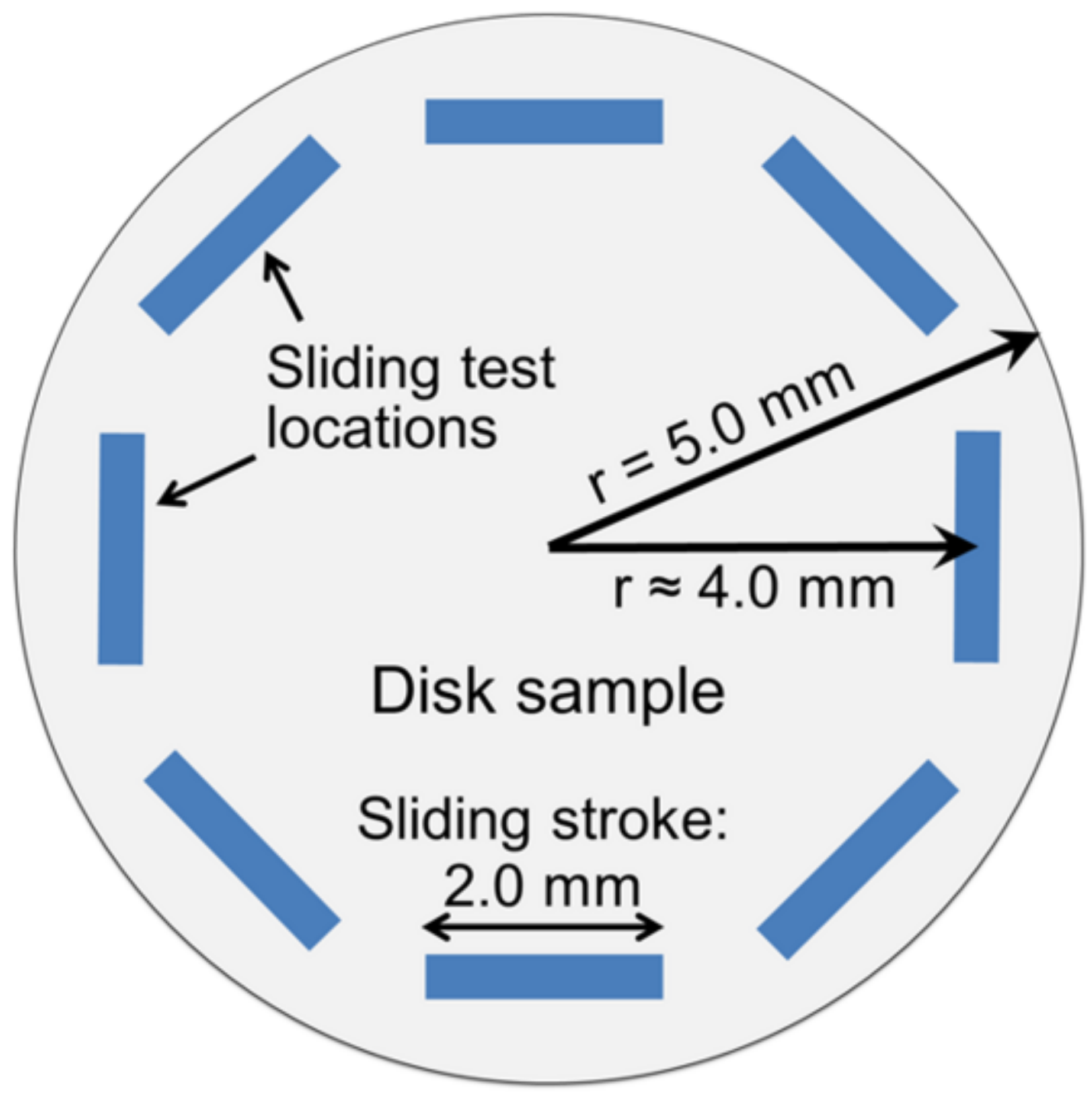




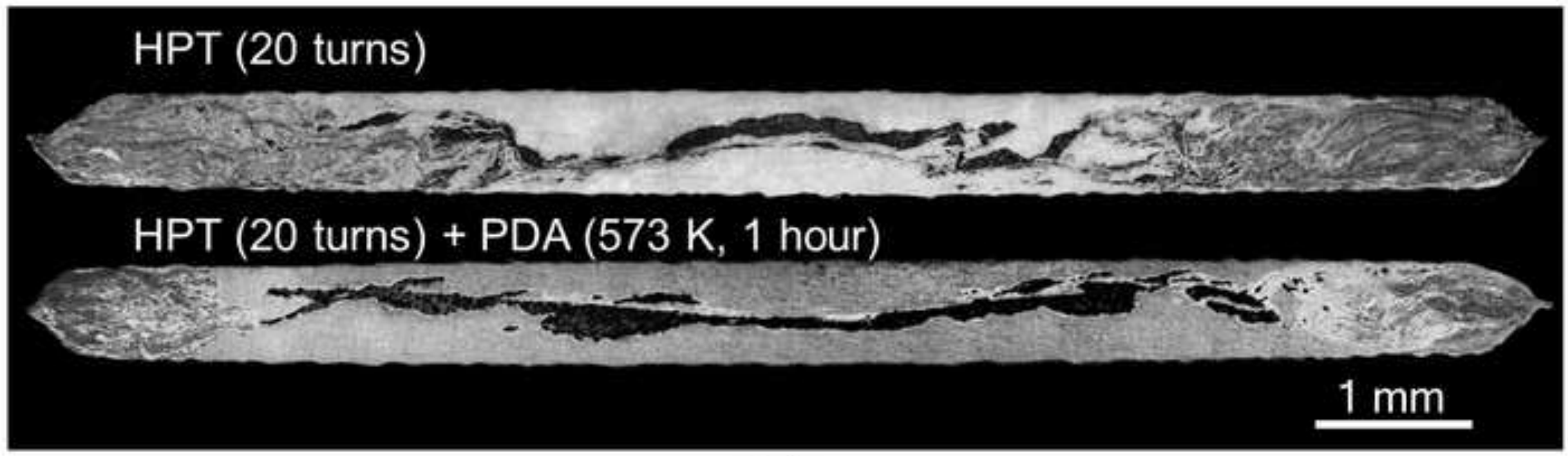

(a)

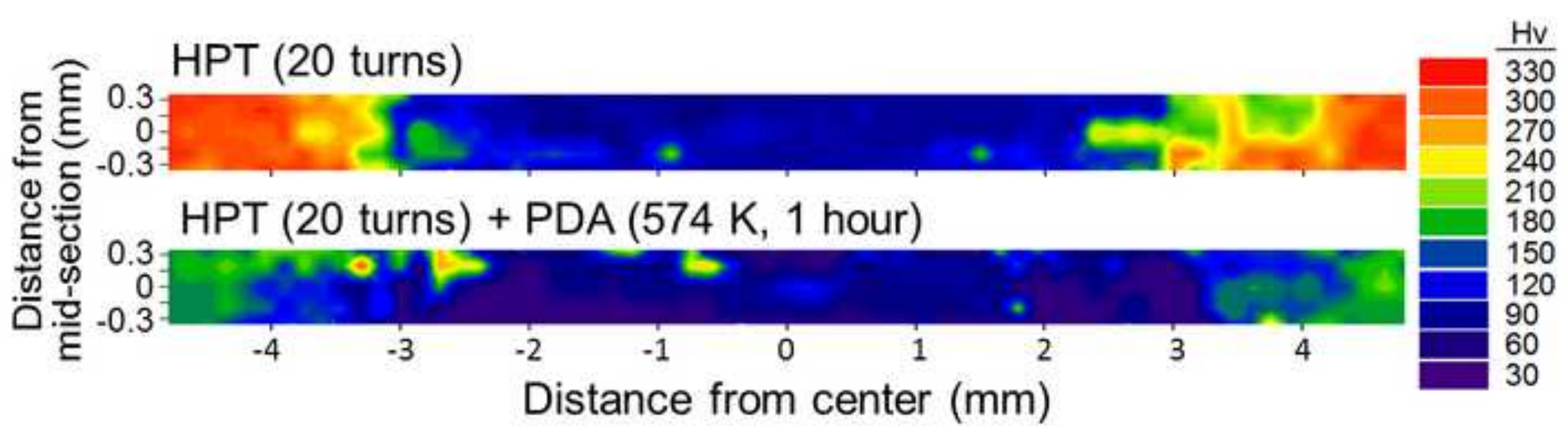

(b)

\section{HPT (20 turns)}

\section{HPT (20 turns) + PDA (573 K, 1 hour)}

\section{$1 \mathrm{~mm}$}


Click here to download high resolution image
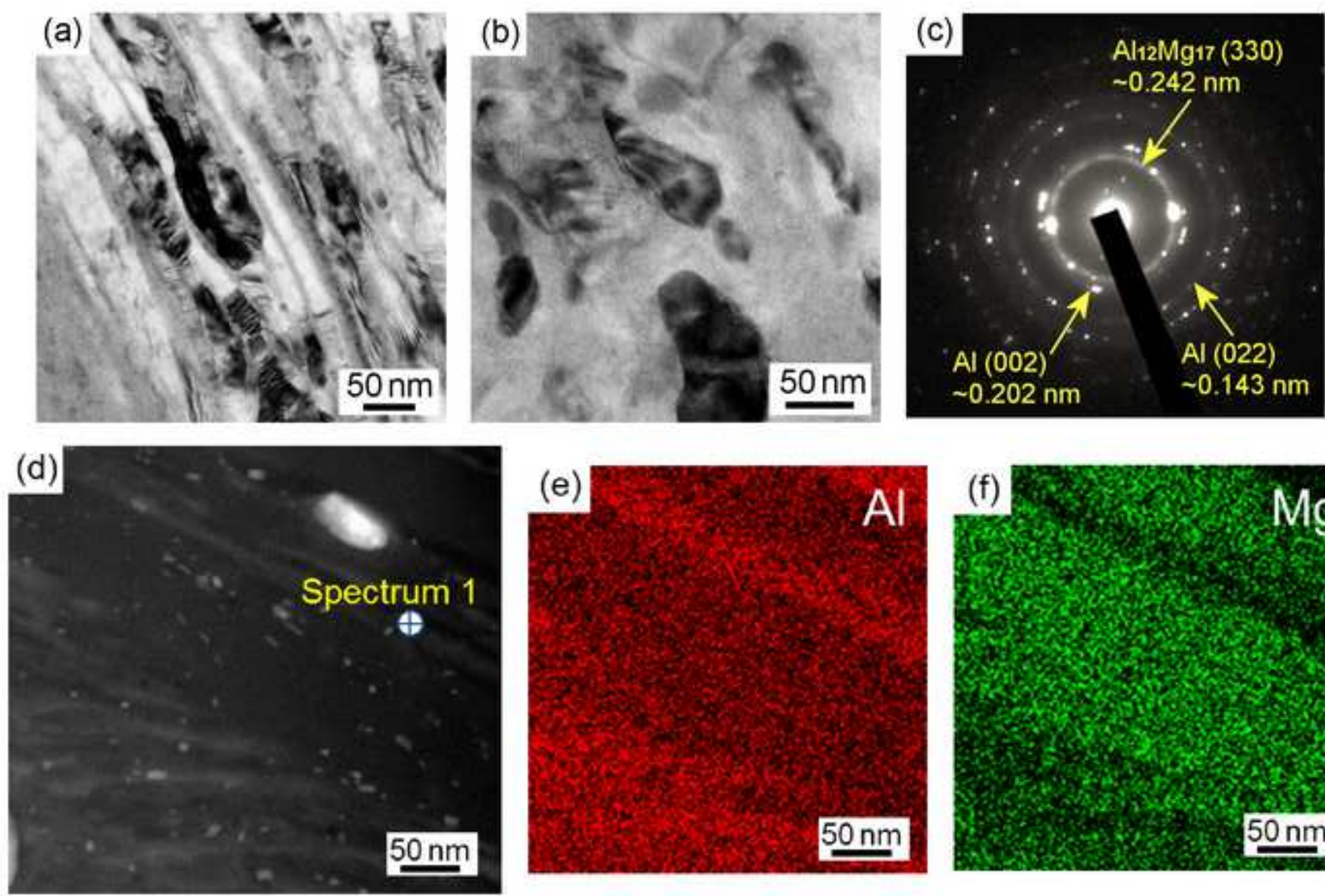

(e)

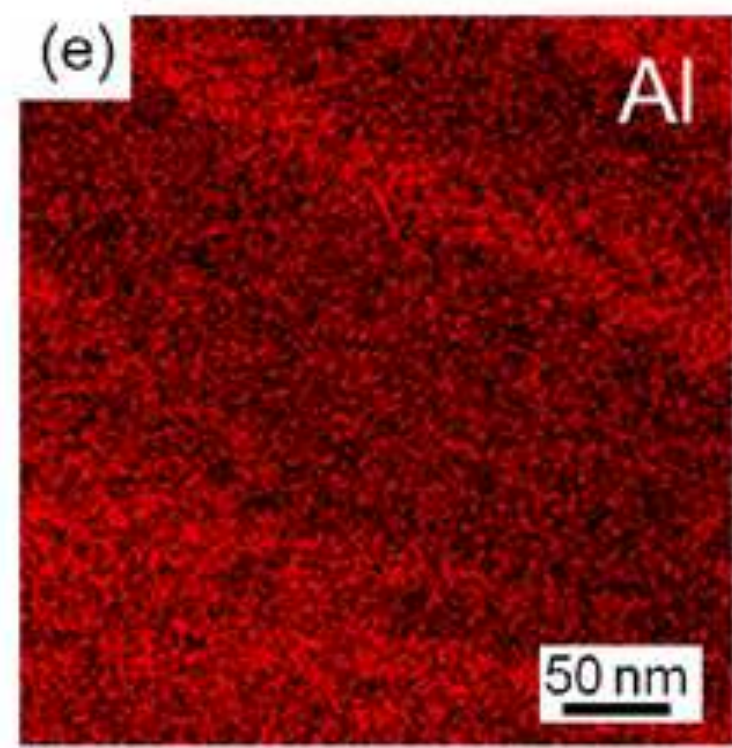

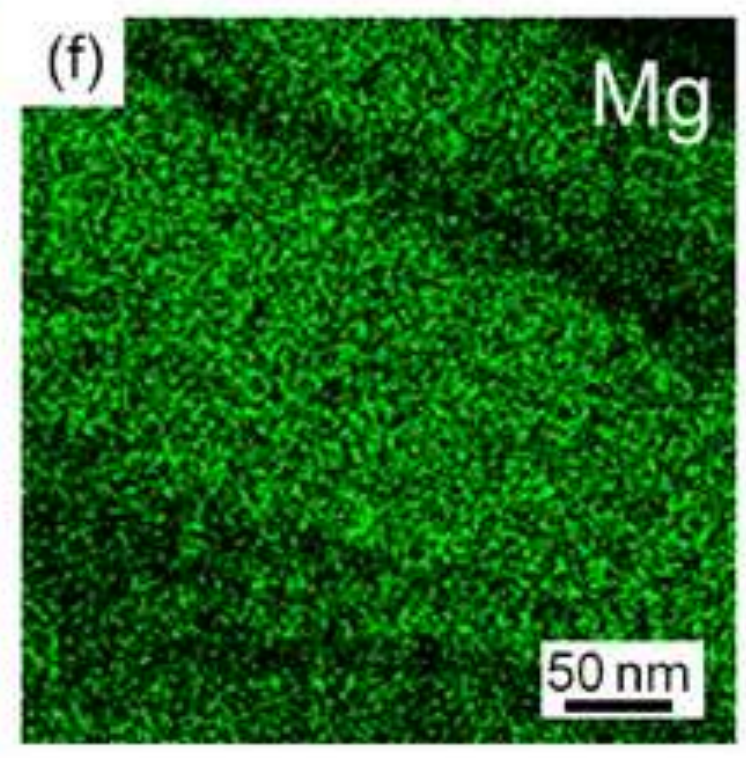


Click here to download high resolution image
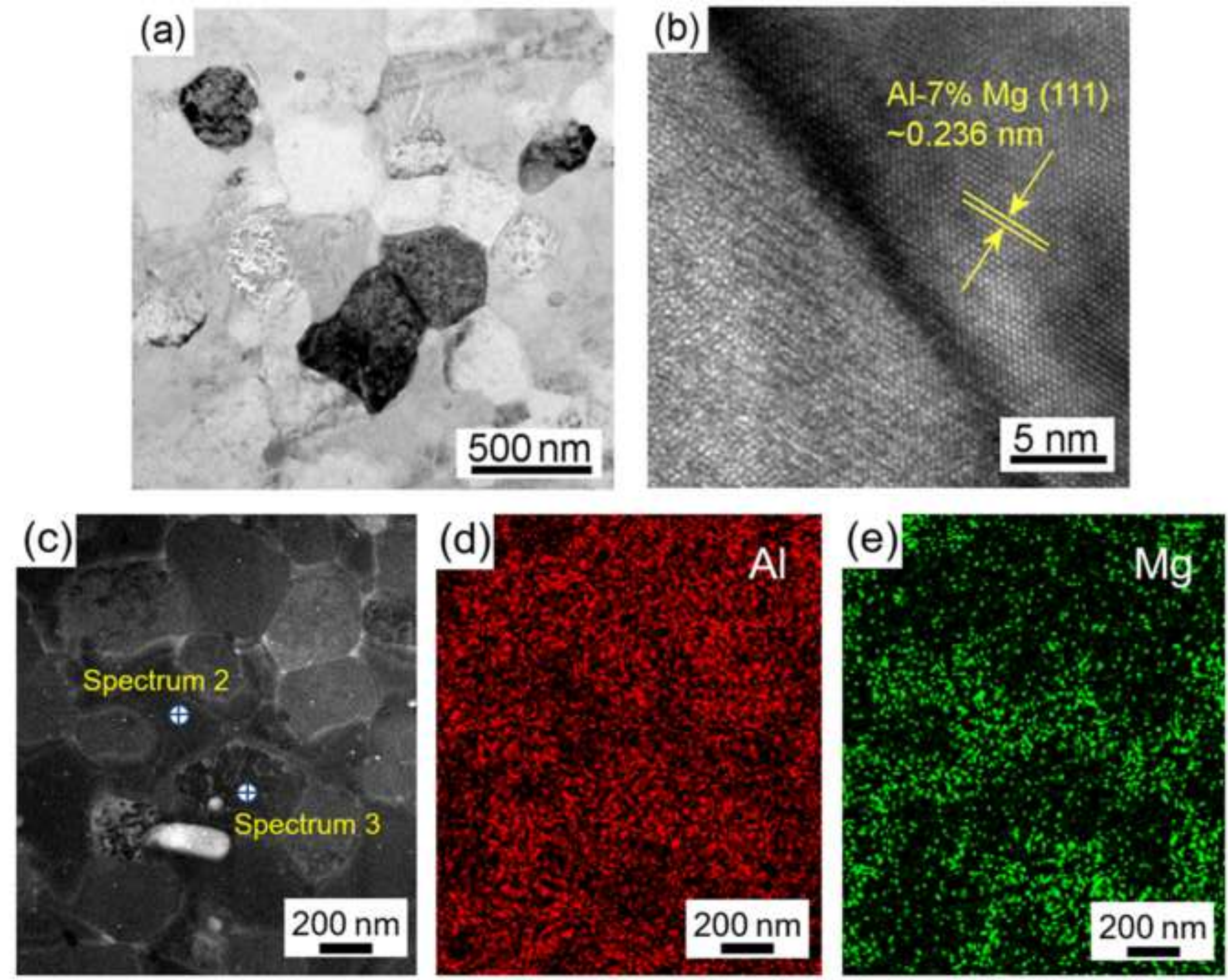


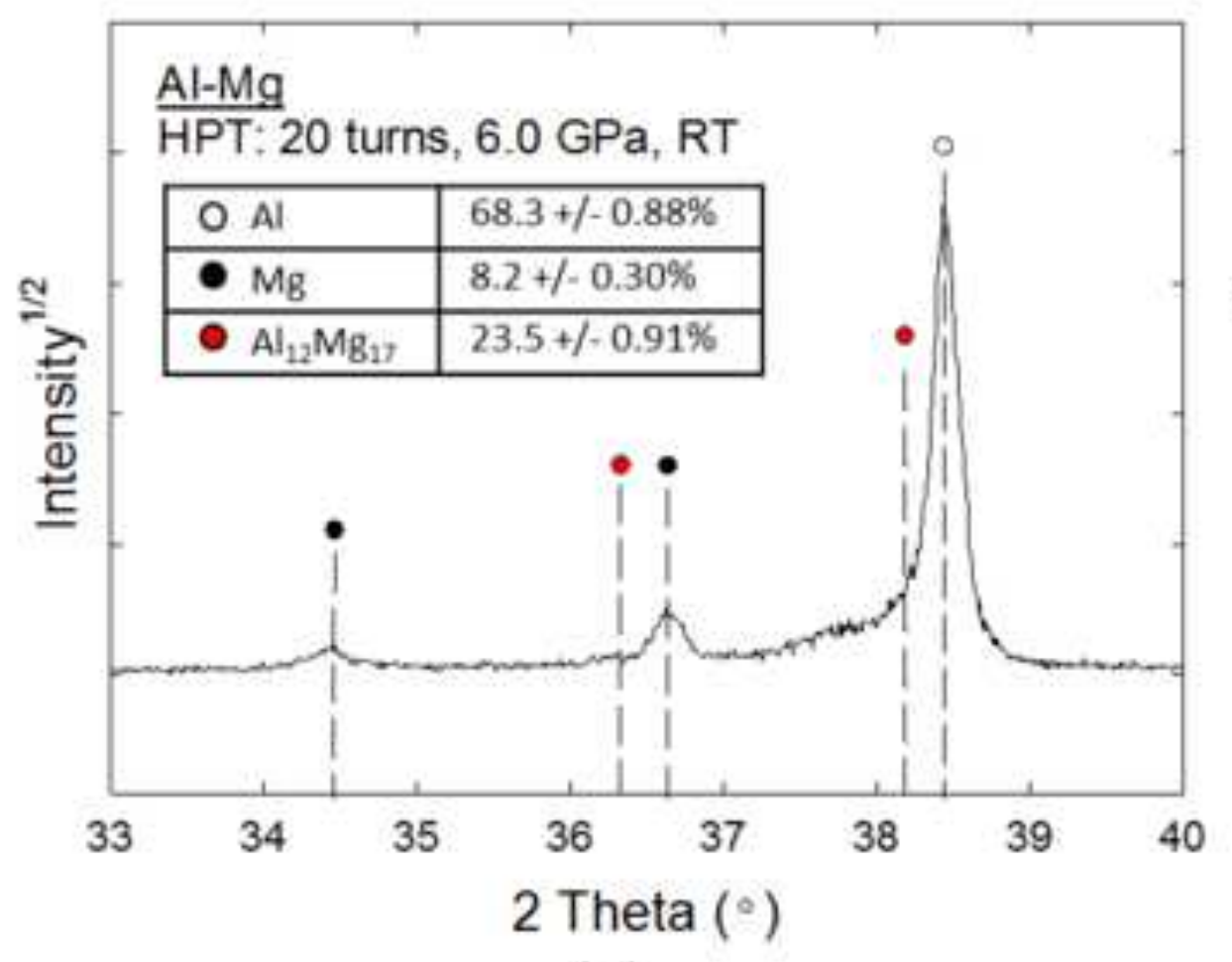

(a)

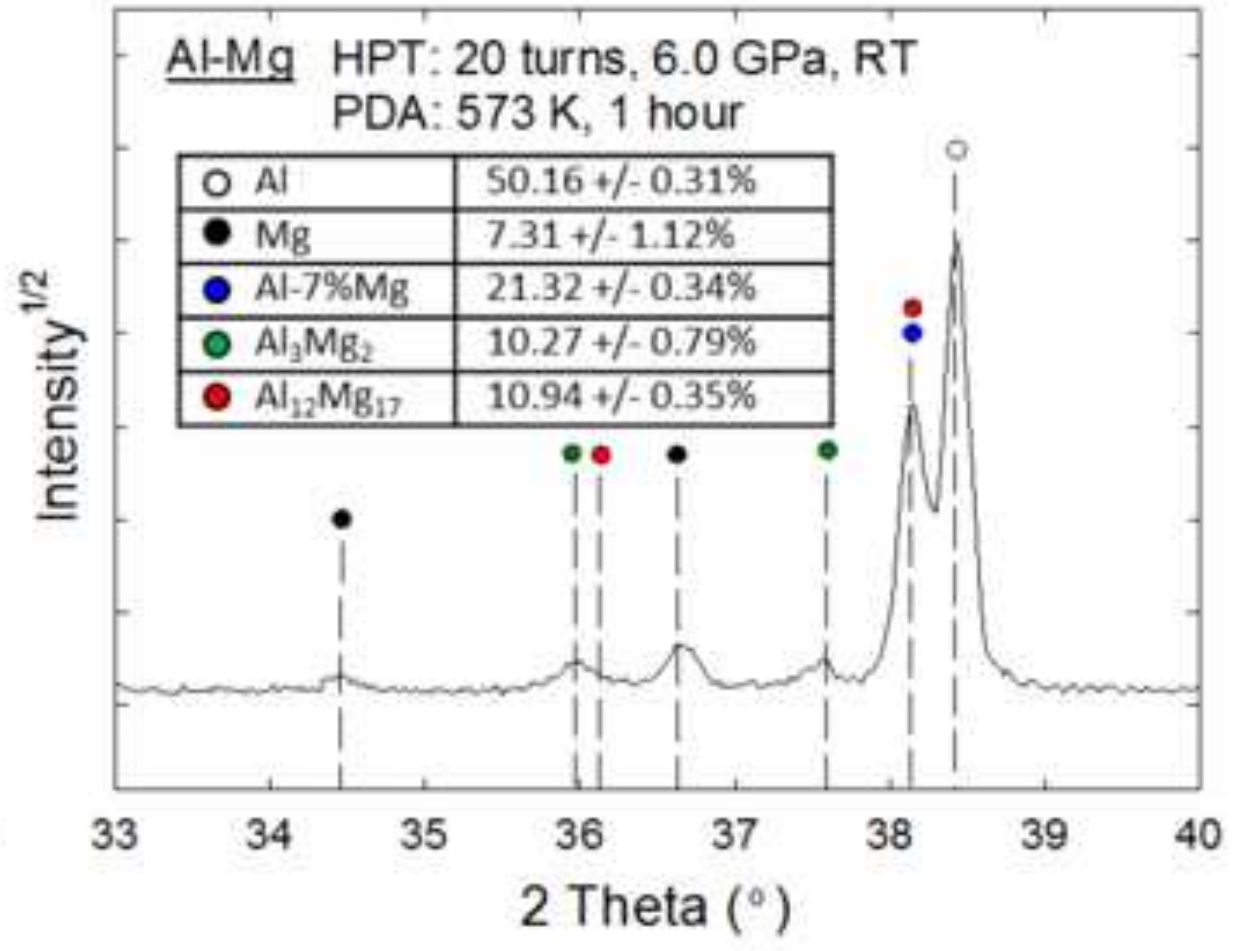

(b) 


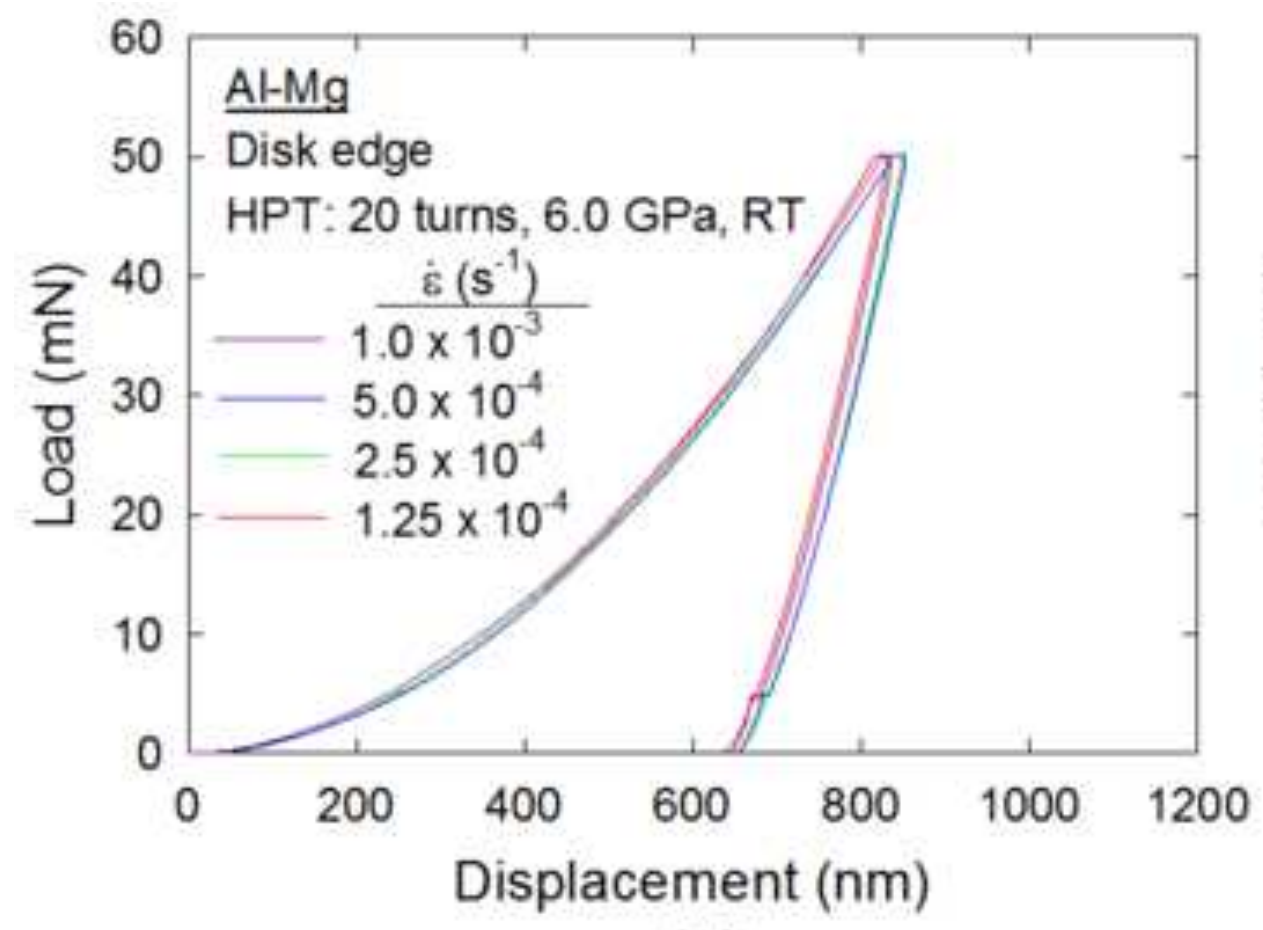

(a)

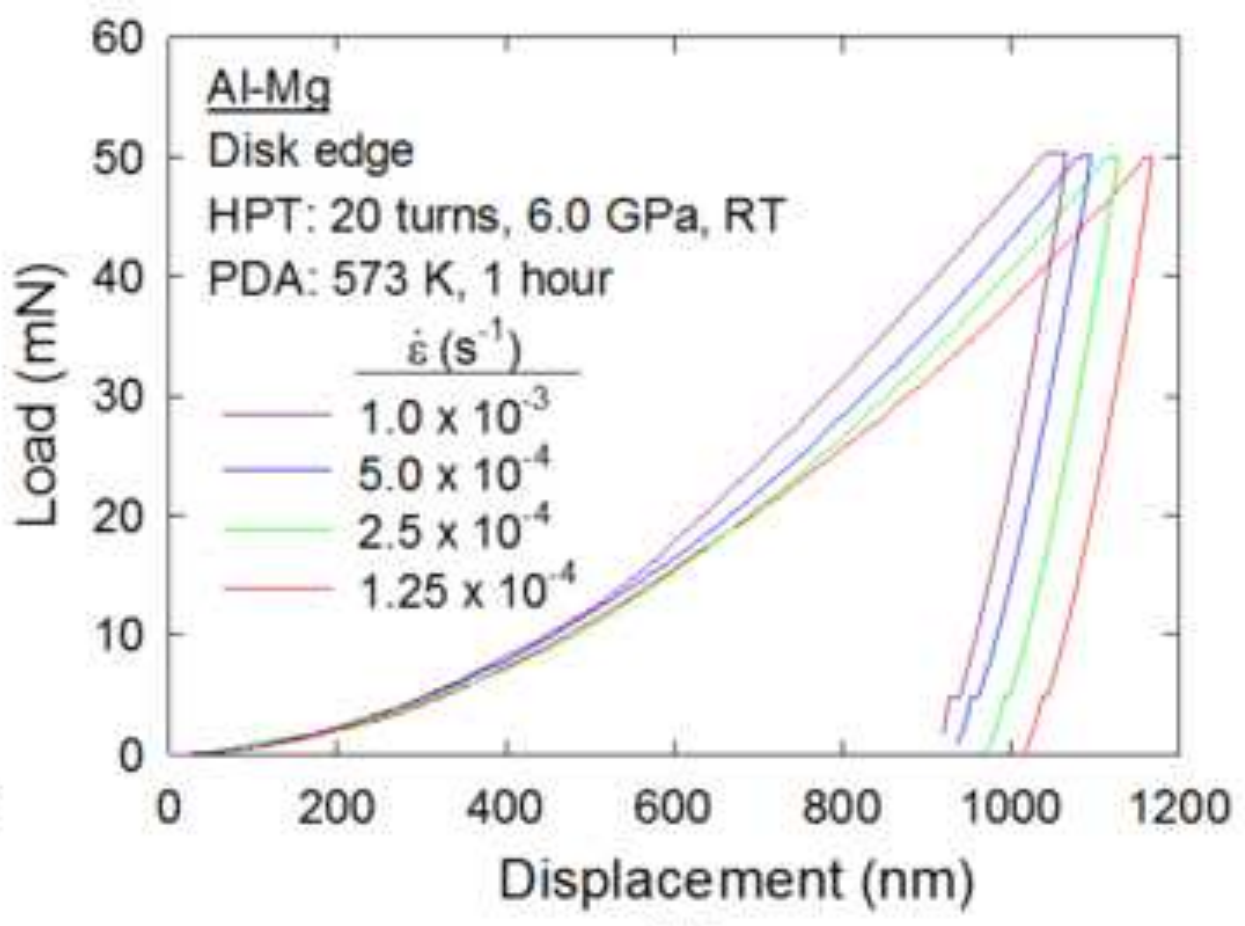

(b) 


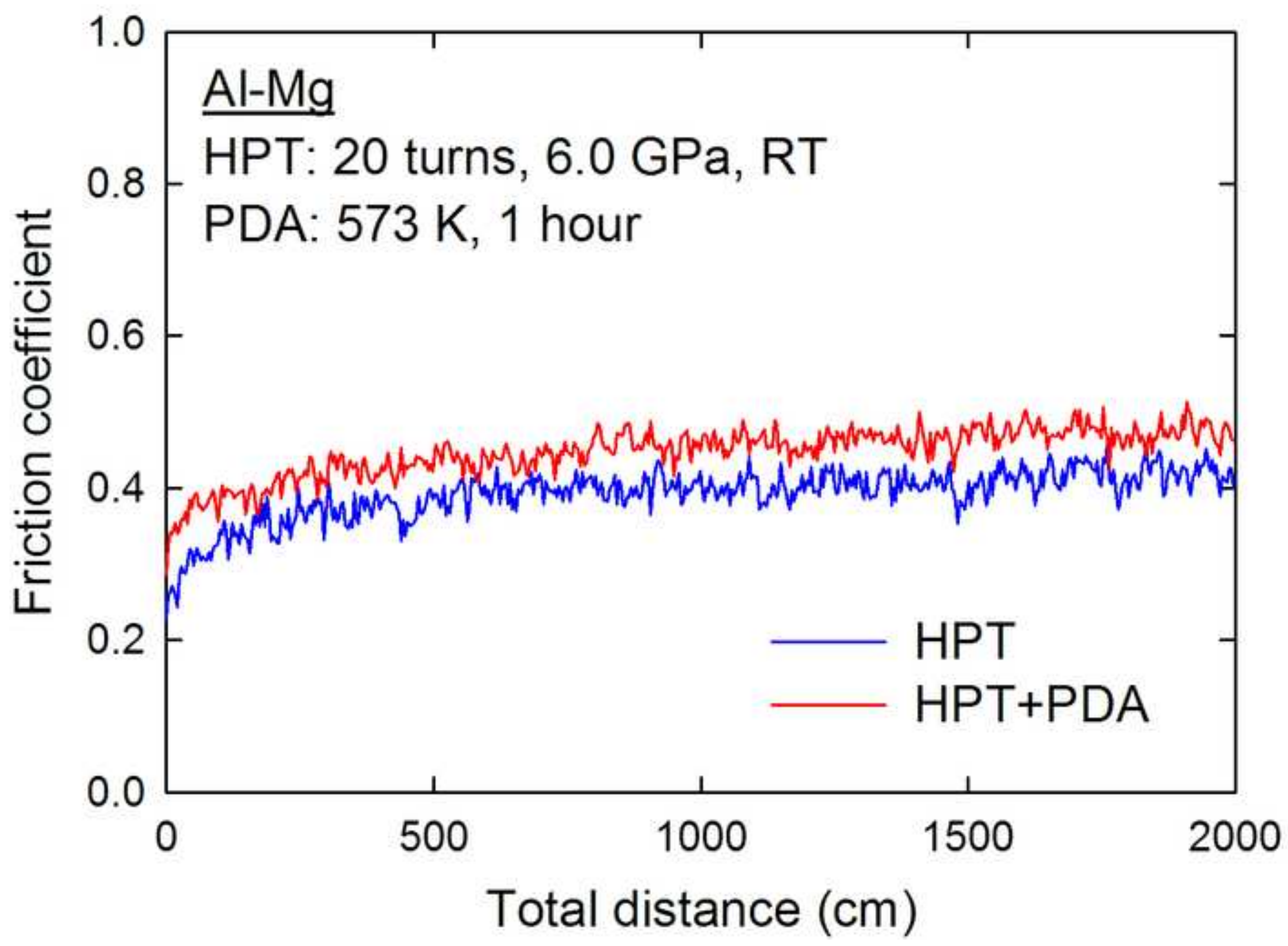


Click here to download high resolution image

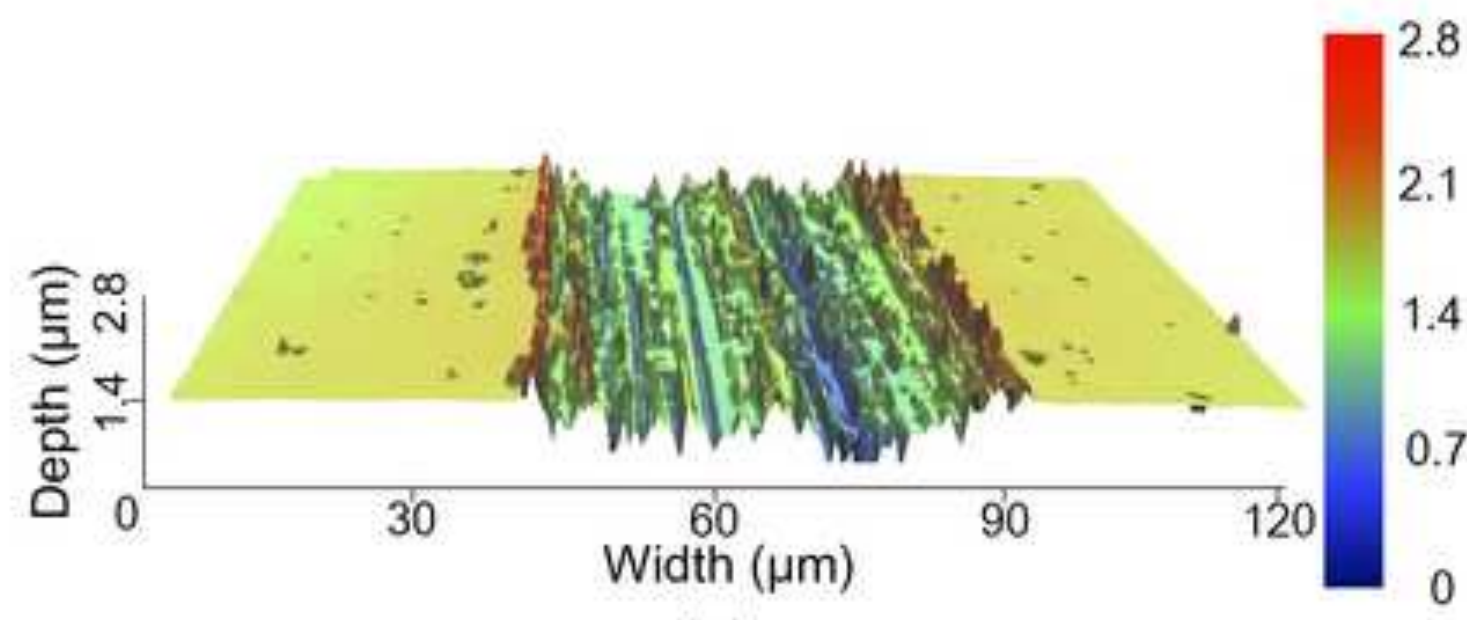

(a)

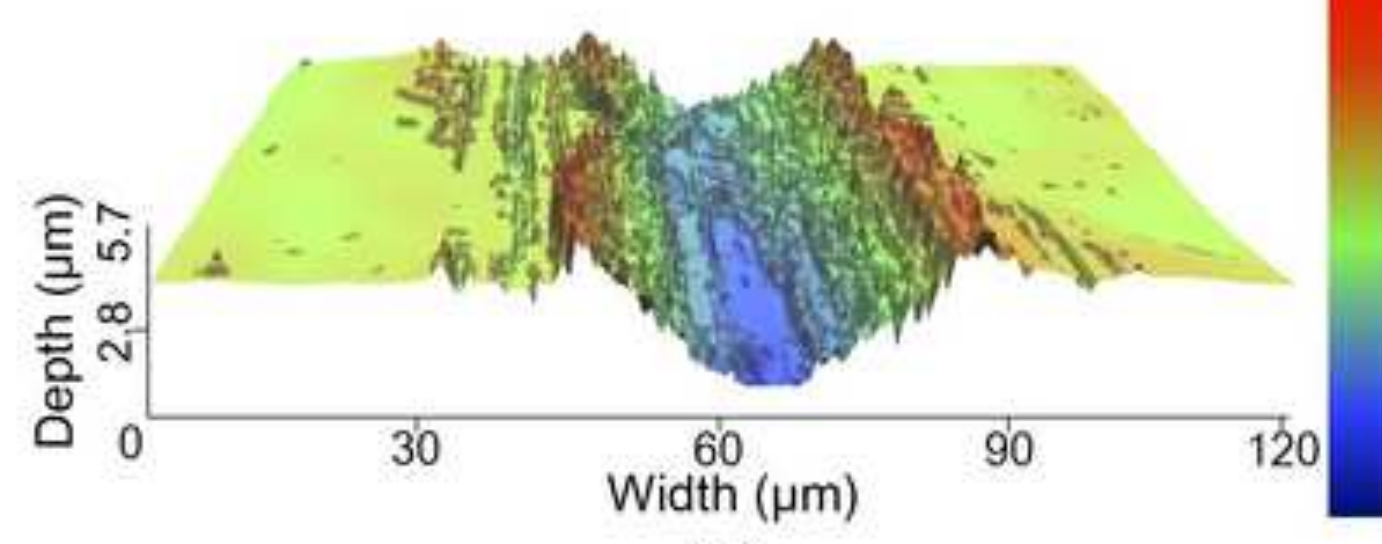

(c)

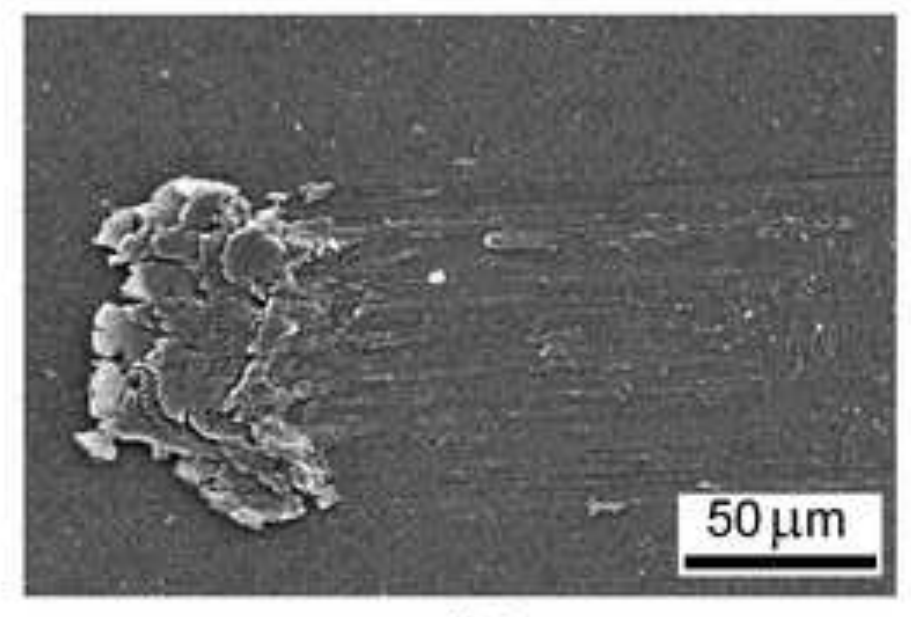

(b)

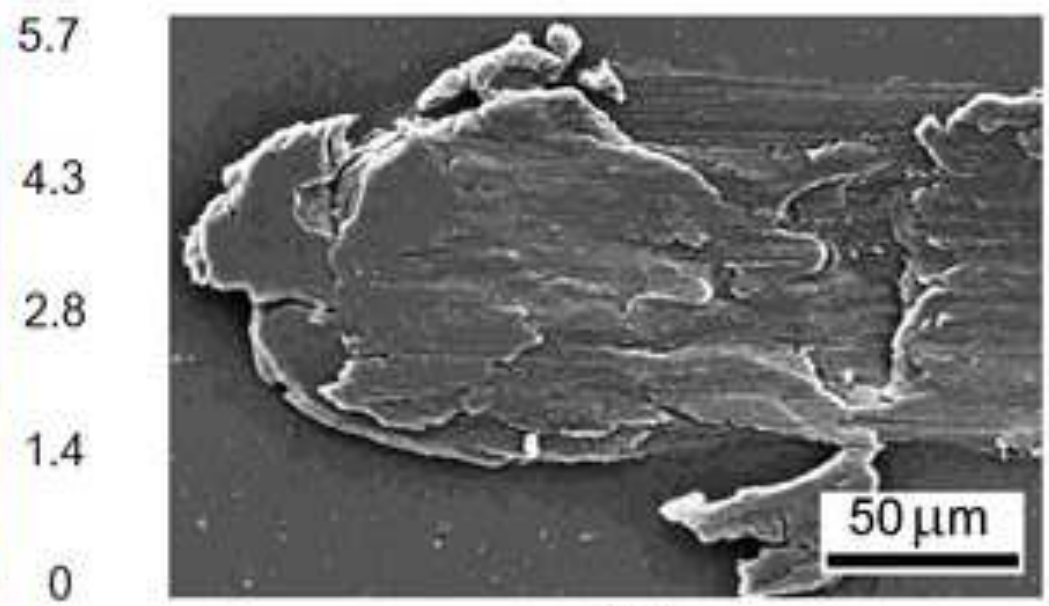

(d) 


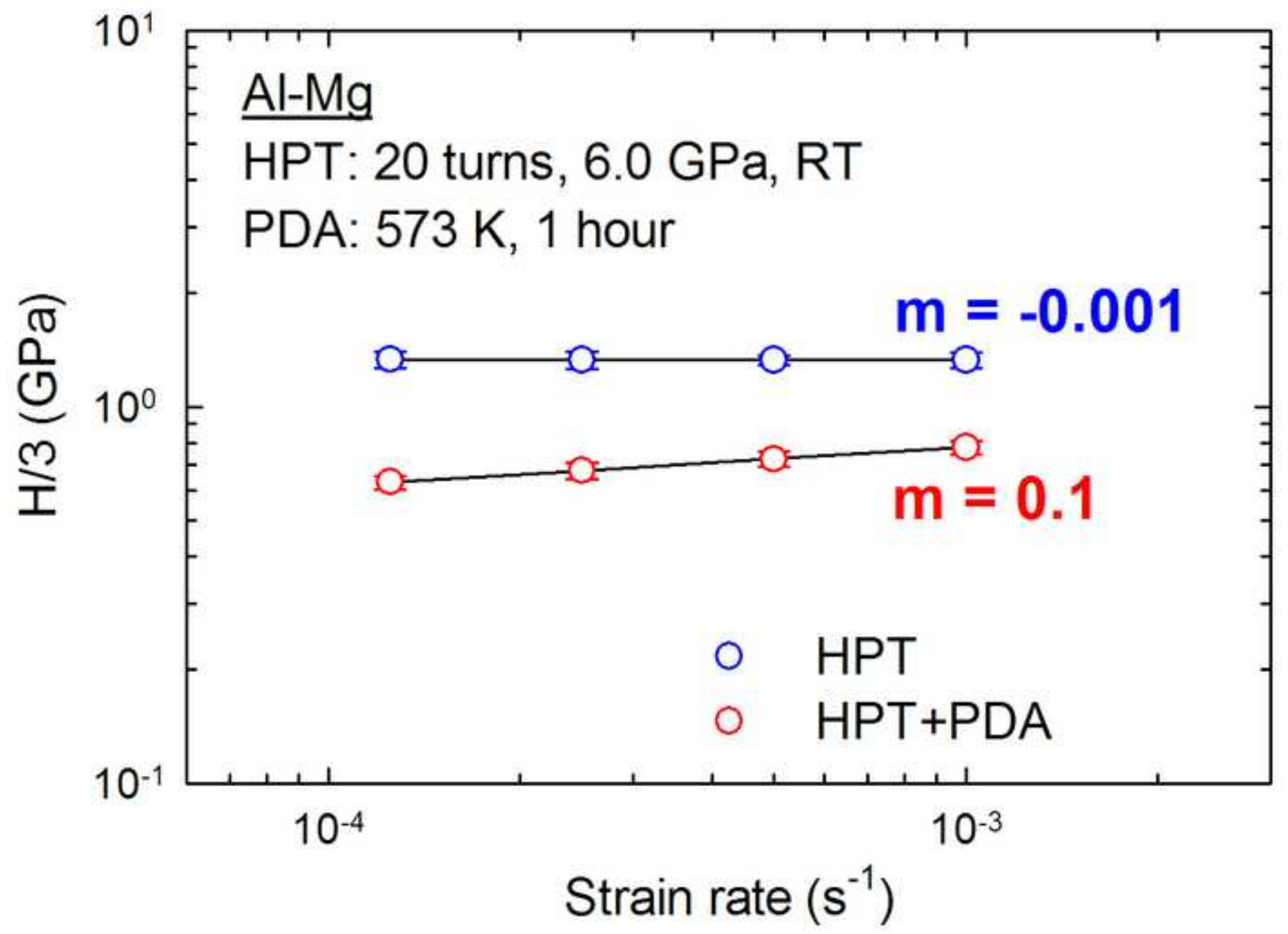


Table 1. The recorded friction coefficients at the initial stage and the steady-state condition for the Al-Mg system after HPT and HPT and PDA and for the Al and Mg alloy disks after HPT.

\begin{tabular}{lcc}
\hline & \multicolumn{2}{c}{ Friction coefficient } \\
\cline { 2 - 3 } & Initial state & Steady-state \\
Al-Mg (HPT: 20 turns) & 0.301 & 0.406 \\
Al-Mg (HPT + PDA) & 0.375 & 0.480 \\
Al-1050 (HPT: 10 turns) & 0.572 & 0.628 \\
ZK60 (HPT: 10 turns) & 0.278 & 0.306 \\
\hline
\end{tabular}


Table 2. The measured weight loss, density, wear volume and the estimated specific wear rate at $P=3 \mathrm{~N}$ and $L=20 \mathrm{~m}$ for the MMNCs in the Al-Mg system after HPT for 20 turns and after HPT and PDA and for the initial Al-1050 and ZK60 alloys after HPT for 10 turns.

\begin{tabular}{lcccc}
\hline & $\begin{array}{c}\text { Weight loss } \\
(\mathrm{g})\end{array}$ & $\begin{array}{c}\text { Density } \\
\left(\mathrm{g} / \mathrm{cm}^{3}\right)\end{array}$ & $\begin{array}{c}\text { Volume loss } \\
\left(\mathrm{mm}^{3}\right)\end{array}$ & $\begin{array}{c}\text { Specific wear rate } \\
\left(\mathrm{mm}^{3} / \mathrm{Nm}\right)\end{array}$ \\
\hline Al-Mg (HPT: 20 turns) & 0.00075 & 2.34 & 0.32 & 0.005 \\
Al-Mg (HPT + PDA) & 0.00165 & 2.34 & 0.71 & 0.012 \\
Al-1050 (HPT: 10 turns) & 0.00230 & 2.73 & 0.84 & 0.014 \\
ZK60 (HPT: 10 turns) & 0.00310 & 1.84 & 1.68 & 0.028 \\
\hline
\end{tabular}

